\title{
Myelinating Glia-Specific Deletion of Fbxo7 in Mice Triggers Axonal Degeneration in the Central Nervous System Together with Peripheral Neuropathy
}

\author{
Sabitha Joseph, ${ }^{1}$ Siv Vingill, ${ }^{2}$-Olaf Jahn, ${ }^{3}$ Robert Fledrich, ${ }^{4}{ }^{-}$Hauke B. Werner, ${ }^{5}$-Istvan Katona, ${ }^{6}$ Wiebke Möbius, ${ }^{7}$ \\ Mišo Mitkovski, ${ }^{8}$ Yuhao Huang, ${ }^{1}$ Joachim Weis, ${ }^{6}$ Michael W. Sereda, ${ }^{9}$ Jörg B. Schulz, ${ }^{1,10,11}$ Klaus-Armin Nave, ${ }^{5}$ \\ and $\odot$ Judith Stegmüller ${ }^{1,11}$ \\ ${ }^{1}$ Department of Neurology, RWTH University Hospital, 52074 Aachen, Germany, ${ }^{2}$ Oxford Parkinson's Disease Centre, University of Oxford, Oxford OX1 \\ 3QX, United Kingdom, ${ }^{3}$ Proteomics Group, Max Planck Institute of Experimental Medicine, 37075 Göttingen, Germany, ${ }^{4}$ Institute of Anatomy, Department \\ of Neuropathology, University Hospital Leipzig, 04103 Leipzig, Germany, ${ }^{5}$ Department of Neurogenetics, Max Planck Institute of Experimental Medicine, \\ 37075 Göttingen, Germany, ${ }^{6}$ Department of Neuropathology, RWTH University Hospital, 52074 Aachen, Germany, ${ }^{7}$ Electron Microscopy Facility, Max \\ Planck Institute of Experimental Medicine, 37075 Göttingen, Germany, ${ }^{8}$ Light Microscopy Facility, Max Planck Institute of Experimental Medicine, 37075 \\ Göttingen, Germany, ${ }^{9}$ Molecular and Translational Neurology, Max Planck Institute of Experimental Medicine, 37075 Göttingen, Germany, ${ }^{10}$ JARA-BRAIN Institute \\ Molecular Neuroscience and Neuroimaging, Forschungszentrum Jülich GmbH and RWTH Aachen University, 52074 Aachen, Germany, and \\ ${ }^{11}$ Research Training Group 2416 MultiSenses-MultiScales, RWTH Aachen University, 52074 Aachen, Germany
}

Myelination of axons facilitates the rapid propagation of electrical signals and the long-term integrity of axons. The ubiquitinproteasome system is essential for proper protein homeostasis, which is particularly crucial for interactions of postmitotic cells. In our study, we examined how the E3 ubiquitin ligase FBX07-SCF (SKP1, Cul1, F-box protein) expressed in myelinating cells affects the axon-myelin unit. Deletion of $\mathrm{Fbxo7}$ in oligodendrocytes and Schwann cells in mice using the Cnp1-Cre driver line led to motor impairment due to hindlimb paresis. It did not result in apoptosis of myelinating cells, nor did it affect the proper myelination of axons or lead to demyelination. It however triggered axonal degeneration in the CNS and resulted in the severe degeneration of axons in the PNS, inducing a full-blown neuropathy. Both the CNS and PNS displayed inflammation, while the PNS was also characterized by fibrosis, massive infiltration of macrophages, and edema. Tamoxifen-induced deletion of $F b x o 7$, after myelination using the Plp1-CreERT2 line, led to a small number of degenerated axons and hence a very mild peripheral neuropathy. Interestingly, loss of $\mathrm{Fbxo} 7$ also resulted in reduced proteasome activity in Schwann cells but not in cerebellar granule neurons, indicating a specific sensitivity of the former cell type. Together, our results demonstrate an essential role for FBX07 in myelinating cells to support associated axons, which is fundamental to the proper developmental establishment and the long-term integrity of the axon-myelin unit.

Key words: axonal degeneration; FBX07; myelin; neuropathy; proteasome

Significance Statement

The myelination of axons facilitates the fast propagation of electrical signals and the trophic support of the myelin-axon unit. Here, we report that deletion of $\mathrm{Fbxo}_{\mathrm{T}}$ in myelinating cells in mice triggered motor impairment but had no effect on myelin biogenesis. Loss of $\mathrm{Fbxo7}$ in myelinating glia, however, led to axonal degeneration in the $\mathrm{CNS}$ and peripheral neuropathy of the axonal type. In addition, we found that Schwann cells were particularly sensitive to $\mathrm{Fbxo7}$ deficiency reflected by reduced proteasome activity. Based on these findings, we conclude that $\mathrm{Fbxo7}$ is essential for the support of the axon-myelin unit and long-term axonal health.

\section{Introduction}

Oligodendrocytes and Schwann cells are the myelinating cells of the CNS and PNS, respectively. They engage in a unique cell-cell interaction with axons and facilitate the rapid propagation of action potentials. A new line of research also established the

lished reagents/analytic tools; K.-A.N. and J.S. designed research; J.S. wrote the first draft of the paper; J.S. edited the paper.

This work was supported by Deutsche Forschungsgemeinschaft Grant STE1117/10-1 to J.S. We thank Hannelore Mader, Claudia Krude, Dr. Anand Goswami (Department of Neuropathology, RWTH Aachen University Hospital), 
trophic support of axons by myelinating cells. This idea was sparked by mouse models that lack the major myelin proteins myelin proteolipid protein (PLP) or CNP (CNPase). Both mutant mouse lines show axonal pathology with little or no demyelination (Griffiths et al., 1998; Lappe-Siefke et al., 2003).

Mechanistic insight came from Fünfschilling et al. (2012) who demonstrated the absence of the mitochondrial complex IV protein COX10 in myelinating cells; thus, the abolishment of their respiration leads to a peripheral neuropathy but no considerable axonal damage in the brain. These experiments indicate that oligodendrocytes provide an energy source to support axons, but Schwann cells apparently fail to do so. Lee et al. (2012) showed evidence that the monocarboxylate transporter MCT1, which is predominantly expressed by oligodendrocytes and responsible for lactate transport, may provide the metabolic connection as $\mathrm{Mct1}^{+/-}$mice display axonopathy without loss of myelin. Hence, the integrity of axons is critically dependent on the metabolic support of interacting myelinating cells.

In addition to energy support, it remains elusive whether further mechanisms in myelinating cells are crucial for the proper support of the axon-myelin unit. There are indications that the ubiquitin proteasome system may play such a role: The Trembler mouse, expressing a mutant myelin protein PMP22, models Charcot-Marie-Tooth (CMT) disease Type 1, which is characterized by hypomyelination and secondary axonal damage. In this mouse, however, Schwann cells show reduced proteasome activity and fail to degrade mutant, aggregation-prone PMP22 (Fortun et al., 2005, 2006).

Peripheral neuropathy is also triggered by systemic proteasome inhibition using bortezomib, a drug typically applied in cancer treatment of multiple myeloma (Cavaletti and Jakubowiak, 2010). In a rat model exposed to bortezomib, both damage to Schwann cells and axonal degeneration was observed (Cavaletti et al., 2007). This raises the question to which extent axons depend on the proper functioning of the ubiquitin-proteasome system (UPS) in myelinating cells?

We have recently identified the F-box protein $\mathrm{FBXO}$ as a regulator of proteasome activity. FBXO7-SCF (Skp1, Cul1, F-box protein) is a multisubunit E3 ubiquitin ligase that binds to the proteasome holoenzyme by directly interacting with the proteasomal subunit $\alpha 2$ (PSMA2) (Vingill et al., 2016). Here, FBXO7 supports the assembly of core particle and regulatory particles. Consequently, FBXO7 KO mice show reduced proteasome activity in the brain (Vingill et al., 2016). In addition to FBXO7's role as a proliferation factor in cancer cells (Laman et al., 2005), which is negligible in postmitotic cells, $\mathrm{FBXO7}$ is instrumental in the initiation of mitochondrial turnover, an event referred to as mitophagy (Burchell et al., 2013). Collectively, FBXO7 is biochemically connected with both mitochondria and proteasomes, and the functioning of these multiprotein complexes is intimately intertwined (Joseph et al., 2018).

Deletion of $\mathrm{Fbxo}$ in neurons leads to a parkinsonism-related phenotype characterized by mild to severe motor impairment but no cell death or axonal pathology in mice (Vingill et al., 2016). Interestingly, FBXO7 shows also a prominent expression in white

Boguscha Sadowski, Torben Ruhwedel (Electron Microscopy, MPI of Experimental Medicine, Göttingen), Dörte Hesse (Proteomics, MPI of Experimental Medicine, Göttingen), and Ramona Jung, Katja Lüders (Department of Neurogenetics, MPI of Experimental Medicine, Göttingen) for excellent technical support; and Prof. Dr. Ueli Suter for providing the PLP1-Cre-ERT2 mouse driver line.

The authors declare no competing financial interests.

Correspondence should be addressed to Judith Stegmüller at jstegmueller@ukaachen.de.

https://doi.org/10.1523/JNEUROSCI.3094-18.2019

Copyright $\odot 2019$ the authors matter (Zhang et al., 2014; Zeisel et al., 2015; Vingill et al., 2016) and in Schwann cells (current study). These findings prompted us to test the hypothesis that deletion of $\mathrm{Fbxo} 7$ from myelinating cells negatively affects proteasome activity and may affect the integrity of myelinating cells and potentially interfere with the axon-myelin interaction.

In this study, we show that deletion of $\mathrm{Fbxo}_{0}$ in myelinating cells causes motor impairment. Interestingly, in the CNS, Fbxo7 deletion does not affect myelination but causes mild axonal degeneration and inflammation. In the PNS, deletion of $\mathrm{Fbxo}_{0}$ in Schwann cells also does not impair myelination, but, strikingly, it induces a marked, progressive peripheral neuropathy of the axonal type.

\section{Materials and Methods}

Mouse experiments

All mice used for this study had a pure C57BL/6N background. The Cnp1-Cre/+ and Plp1-CreERT2/+ mouse lines were strictly kept heterozygous. The mice were housed under standard $12 \mathrm{~h}$ light-dark cycle with sufficient food and water in the mouse facility of the Max Planck Institute for Experimental Medicine in Göttingen or the mouse facility of the RWTH University Hospital (Aachen, Germany). Experiments were performed according to the guidelines for German animal welfare and were approved by the "Landesamt für Verbraucherschutz und Lebensmittelsicherheit" of Lower Saxony, Germany and the "Landesamt für Natur, Umwelt und Verbraucherschutz Nordrhein-Westfalen," Germany.

\section{Generation of conditional Fbxo7-KO mouse lines}

The conventional Fbxo7 KO mouse line was generated as described previously (Vingill et al., 2016). To establish new conditional mouse lines, homozygous Fbxo $7 f l / f l$ mice, in which exon 4 was flanked by loxP sites, were either mated with heterozygous $\mathrm{Cnp1}-\mathrm{Cre} /+$ mice (Lappe-Siefke et al., 2003) or with heterozygous tamoxifen-inducible Plp1-CreERT2/+ mice (Leone et al., 2003). In these conditional KO mice, FBXO7 was deleted from myelinating cells. For further reference, Cnp1-Cre/+; Fbxo7fl/fl and Plp1-CreERT2/+;Fbxo7fl/fl mice are referred to as Cnp1Cre;flffl and Plp1-CreERT2;fl/fl, respectively. For the genotyping of male and female mice, the following primers were used: LacZ cassette (forward): $5^{\prime}$-attccagctgagcgccggtcgc-3', (reverse): $5^{\prime}$-gcgagctcagaccataa cttcgtata-3'; Fbxo7 floxed (forward): $5^{\prime}$-tcagcatgggtttgttaagcatctacta-3', (reverse): $5^{\prime}$-ggtctagatatctcgacataacttcgtata-3'; Fbxo7 WT (forward): $5^{\prime}-$ gggctgtatgaaggaagtgctatt- $3^{\prime}, \quad$ (reverse): $5^{\prime}$-ccctgagagtgaagggtgctgttc- $3^{\prime}$; and Cre allele (forward): $5^{\prime}$-cagggtgttataagcaatccc- $3^{\prime}$, (reverse): $5^{\prime}$ cctggaaaatgcttctgtccg-3'.

Mice were killed at 4 months of age as they reached the underweight criteria (weight loss $\geq 20 \%$ ) established in the animal protocol.

\section{Tamoxifen-induced knockdown of Fbxo7}

In the inducible conditional Plp1-CreERT2;flffl mouse line, Cre recombinase expression is only activated upon tamoxifen injection. Hence, $100 \mu \mathrm{l}$ of $20 \mathrm{mg} / \mathrm{ml}$ tamoxifen dissolved in corn oil was intraperitoneally injected in mice for 5 consecutive days. The total amount of injected tamoxifen was $10 \mathrm{mg}$. The mice were injected with tamoxifen at 2 months of age, when myelination was completed. Control mice lacking the Plp1-CreERT2 insertion were also injected with the same amount of tamoxifen.

\section{Electrophysiological measurement}

Electrophysiology was performed on 2-month-old, male and female Cnp1-Cre; fl/fl and control mice. Mice were anesthetized with ketamine hydrochloride/xylazine hydrochloride $(100 \mathrm{mg} / \mathrm{kg}$ body weight $/ 8 \mathrm{mg} / \mathrm{kg}$ body weight, Medistar). A pair of steel needle electrodes (Schuler Medizintechnik) was placed subcutaneously along the nerve at sciatic notch ( proximal stimulation). A second pair of electrodes was placed along the tibial nerve above the ankle (distal stimulation). Supramaximal square wave pulses lasting $100 \mathrm{~ms}$ were delivered using a Toennies Neuroscreen (Jaeger). Compound muscle action potential (CMAP) was recorded 
from the intrinsic foot muscles using steel electrodes. Both amplitudes and latencies of CMAP were determined. The distance between the two sites of stimulation was measured alongside the skin surface with fully extended legs, and nerve conduction velocities (NCVs) were calculated automatically from sciatic nerve latency measurements. The distal motor latency (DML) was measured from the delay between initiating a stimulus and the evoked potential. Statistical analyses were performed by applying the Student's $t$ test. The collaborating researchers were given the mice unaware of genotype to perform analyses in a blinded manner.

\section{Behavioral analyses}

Only male mice were used for behavioral analyses. Male Cnp1-Cre; fl/fl and control mice were tested at 6 weeks of age, whereas male Plp1CreERT2; fl/fl and control mice were tested at 5, 7, and 9 months of age. All tests were conducted under standardized conditions, at fixed light intensity of 90 lux and protected from disturbance. Before each session, mice were allowed to acclimate for $30 \mathrm{~min}$ in the test room. Afterward, the weight of the animals was determined and the behavioral tests were performed in a distinct order: first elevated plus maze for assessing anxiety, then open field test for ambulation and exploratory behavior, followed by hindlimb clasping test, inverted grid, pole test, wire hang, balance beam, and Rotarod for motor endurance and coordination. For sensory assessment, the hot plate test was performed. The animals were monitored using the software Viewer from Biobserve, and obtained data were analyzed using Microsoft Excel and GraphPad Prism. The researcher tested the mice's behavior in a blinded manner. No genotypes were written on cage cards. Ear tag numbers were matched with genotypes following the behavior tests and statistical analyses.

\section{Elevated plus maze}

To evaluate the anxiety of mice, an elevated plus maze test was conducted according to the published protocol (Pellow et al., 1985). Mice were placed in the center of the plus maze $(5 \times 30 \mathrm{~cm}, 15 \mathrm{~cm}$ wall height, $40 \mathrm{~cm}$ elevated from ground) facing an open arm, and both activity and exploratory behavior were recorded for $5 \mathrm{~min}$ with the Viewer software. The time spent in open and closed arms was analyzed, as intensive time spent in an open arm indicates reduced anxiety.

\section{Open field}

General locomotion and exploratory behavior was measured in an open field test, as previously demonstrated (Hall and Ballachey, 1932). The round arena had a diameter of $60 \mathrm{~cm}$ and was surrounded by a $20-\mathrm{cm}-$ high wall. The mice were placed in the center, and movement was monitored for $7 \mathrm{~min}$ with the Viewer animal tracking system. The traveled distance and time spent in different zones were analyzed.

\section{Hindlimb clasping test}

To assess signs of neurological deficits and neurodegenerative disease progression, a modified form of the tail suspension test described by Steru et al. (1985) was performed. Mice were lifted by the proximal tail for $10 \mathrm{~s}$. The position of the hind limbs was scored from 0 to 3: with 3 representing normal, splayed hind limbs and 0 indicating strong clasping of hindpaws. The average of 3 trials represents the final score. In-between repeated measurements, a $30 \mathrm{~s}$ pause was given.

\section{Inverted grid}

Muscle strength was assessed by the inverted grid test. Therefore, mice were placed onto the grid of their home cage, and the grid was inverted. The time mice could hold on to the inverted grid was measured with a cutoff time at $60 \mathrm{~s}$. Three repeated measurements were performed with a break of $1 \mathrm{~min}$ in between, and the average of all measurements was calculated.

\section{Pole test}

The pole test has been previously described as an assessment for basal ganglia-related motor function (Ogawa et al., 1985; Matsuura et al., 1997). Mice were placed onto a vertical pole ( $50 \mathrm{~cm}$ long, $1 \mathrm{~cm}$ diameter) facing upward and had to turn around to climb down the pole. The time needed to reach the bottom of the pole was measured. Three trials with a $1 \mathrm{~min}$ break were performed. The average of all trials was calculated.

\section{Wire hang}

Another test for muscle strength is the wire hang test, as previously described (Aartsma-Rus and van Putten, 2014). Mice were placed with their front paws in the middle of a wire $(80 \mathrm{~cm}$ long, $1 \mathrm{~mm}$ diameter, and $30 \mathrm{~cm}$ above surface) suspended between two poles. The time needed to reach one of the poles was measured. Three repeats were performed with an interval of $1 \mathrm{~min}$, and the average time was calculated.

\section{Balance beam}

For testing balance and coordination, a balance beam test was conducted as previously described (Luong et al., 2011). The mice were placed on a 6-mm- or a 12-mm-wide and $80-\mathrm{cm}$-long beam. The beam is located 50 $\mathrm{cm}$ above the ground, with a black box $(15 \times 15 \times 15 \mathrm{~cm})$ attached on one end. Once the mice were placed on the opposite end of the beam, time as well as numbers of slips were counted until the black box was reached. For each beam, 3 repetitions were performed, with 1 min break in between and 10 min resting time in between beams. The average time required to cross the beam as well as average number of slips were calculated.

\section{Rotarod}

While subjecting the mice to a Rotarod test, motor coordination and endurance were tested. The accelerating protocol of the Rotarod (Ugo Basile) was set to $4-40 \mathrm{rpm}$ in $3 \mathrm{~min}$. The average time spent on the rotating rod was measured, and each mouse was tested 3 times, with a 10 min break in between. The cutoff time was set for $5 \mathrm{~min}$. The test was performed at 3 time points $(0,3$, and $24 \mathrm{~h})$.

\section{Hot plate}

To assess sensory deficits, a hot plate test was conducted (Eddy and Leimbach, 1953). Mice were placed in a $1000 \mathrm{ml}$ round glass beaker on a $55^{\circ} \mathrm{C}$ metal plate. Once the animals showed any sign of irritation due to the heat, the time was stopped and the mice were immediately removed from the plate. A cutoff time of $30 \mathrm{~s}$ was set. Three repeated measurements were taken with a 10 min break in between. The average time was calculated.

\section{Transcardial perfusion and fixation}

Mice were anesthetized by intraperitoneal injection of $10 \%$ ketamine (CP Pharma) and 5\% xylazine (Medistar Arzneimittelvertrieb). The animals were then transcardially perfused with sterile PBS, followed by $4 \%$ PFA/PBS or Karlsson and Schultz buffer (Karlsson and Schultz, 1965; Schultz and Karlsson, 1965). The tissue of interest was dissected and incubated in $4 \%$ PFA/4\% sucrose in PBS or Karlsson and Schultz buffer overnight at $4^{\circ} \mathrm{C}$ and then further processed, depending on the experimental procedure.

\section{Immunohistochemistry of cryosections}

The PFA-fixated samples of Cnp1-Cre;fl/fl mice and controls were incubated in $30 \%$ sucrose/PBS overnight at $4^{\circ} \mathrm{C}$, embedded it OCT (Tissue Tek, Sakura), and cut in $20 \mu \mathrm{m}$ thin cross sections (spinal cord) or longitudinal sections (sciatic nerve) using a cryostat (CM3050 S, Leica Microsystems). For fluorescent staining, free-floating cryosections were washed twice with PBST, permeabilized with $0.5 \%$ Triton X-100/PBS for $30 \mathrm{~min}$, and blocked for $1 \mathrm{~h}$ in blocking solution (10\% goat serum, $2 \%$ BSA, $0.5 \%$ Triton X-100 in PBS). After washing the samples with PBST, they were incubated overnight at $4^{\circ} \mathrm{C}$ in antibody solution $(10 \%$ goat serum, $2 \%$ BSA in PBS) containing the respective dilution of the primary antibody. The samples were washed 3 times with PBST and incubated for $1 \mathrm{~h}$ at room temperature in a secondary antibody diluted in antibody solution and DAPI. The samples were washed three times with PBST. Finally, the sections were mounted onto a glass slide and mounted with Mowiol mounting medium (6 g glycerol, $2.4 \mathrm{~g}$ Mowiol 4-88, $6 \mathrm{ml} \mathrm{H}_{2} \mathrm{O}$, $12 \mathrm{ml} 0.2 \mathrm{M}$ Tris-HCl, pH 8.5, $25 \mathrm{mg} / \mathrm{ml}$ 1,4-diazabicyclo(2.2.2)octane). Pictures were taken using the Olympus BX51 and analyzed using ImageJ or Fiji (Schindelin et al., 2012; Schneider et al., 2012). The pictures were quantified using a customized macro written by Dr. Miso Mitkovski, which quantified the area stained in pixels, as well as the total area, to calculate the percentage of area stained. To minimize bias, several immu- 
nostained sections of each brain were blinded and subjected to analyses. For statistical analyses, GraphPad Prism was used.

\section{Immunohistochemistry of paraffin sections}

PFA-fixated brains of male Cnp1-Cre;fl/fl mice and controls were embedded in paraffin using the standard protocol. Brains were cut into 5 $\mu \mathrm{m}$ sagittal sections using a microtome (HM 430, Thermo Fischer Scientific), mounted on glass slides, and stained using the LSAB2 detection system. After deparaffinization, the sections were boiled in citrate buffer for antigen retrieval for $10 \mathrm{~min}$, cooled down, and incubated in Tris buffer $+2 \%$ milk for $5 \mathrm{~min}$. The slides were incubated for $5 \mathrm{~min}$ in $3 \%$ $\mathrm{H}_{2} \mathrm{O}_{2}$ to inactivate endogenous peroxidase. After rinsing with Tris-buffer + milk, the sections were blocked in blocking buffer (20\% goat serum in BSA/PBS) for 10 min and incubated in primary antibody diluted in BSA/ PBS at $4^{\circ} \mathrm{C}$ overnight. The slides were rinsed with Tris buffer + milk and subjected to DAB staining using the LSAB2 kit (Dako). Following DAB staining, the sections were counterstained with hematoxylin and Scott's solution (Thermo Fisher Scientific). The sections were dehydrated and mounted using Eukitt mounting medium (Kindler). Images were taken with the Axiophot microscope (Carl Zeiss), and pictures were analyzed using ImageJ and a custom-made macro provided by Dr. Miso Mitkovski. Here, the DAB-positive areas were converted into a distinct signal to measure the percentage of DAB-positive area, with regard to the total area of interest. To minimize bias, several stained sections of each brain were blinded and subjected to analyses. Graphs and statistical analyses were performed using GraphPad Prism.

\section{TUNEL assays}

Sagittal brain sections of $5 \mu \mathrm{m}$ thickness from Cnp1-Cre; fl/fl mice and controls were stained for apoptotic cells using the DeadEnd Colorimetric TUNEL System kit (Promega). The sections were mounted with AquaPoly/Mount (Polysciences) and quantified with the same ImageJ macro by Dr. Mitkovski as described earlier.

\section{Gallyas silver impregnation}

Myelin fibers were stained using the Gallyas protocol (Gallyas, 1979); $5 \mu \mathrm{m}$ sagittal brain sections of male Cnp-Cre;fl/fl and control mice were deparaffinized and incubated in a 2:1 mixture of pyridine and acetic anhydride for $30 \mathrm{~min}$. The samples were rinsed 3 times with $\mathrm{H}_{2} \mathrm{O}$ and incubated in incubating solution (12.5 mM NH $\mathrm{m}_{4} \mathrm{NO}_{3}, 5.9 \mathrm{~mm} \mathrm{AgNO}_{3}, 3$ $\mathrm{mm} \mathrm{NaOH}$ ) for $10 \mathrm{~min}$. Slides were washed 3 times with $0.5 \%$ acetic acid and incubated in developing solution ( $50 \%$ of $\left[472 \mathrm{~mm} \mathrm{Na}_{2} \mathrm{CO}_{3}\right], 35 \%$ of [25 mM NH $\mathrm{NO}_{3}, 11.8 \mathrm{~mm} \mathrm{AgNO}_{3}, 3.5 \mathrm{~mm}$ silicotungstic acid], 15\% of [25 mm NH $\mathrm{mH}_{4} \mathrm{NO}, 11.8 \mathrm{~mm} \mathrm{AgNO}_{3}, 3.5 \mathrm{~mm}$ silicotungstic acid, 1.89\% formaldehyde]) for 3-15 min until the desired intensity of staining was reached. The reaction was stopped by applying $1 \%$ acetic acid. The samples were washed twice with $\mathrm{H}_{2} \mathrm{O}$ and incubated in $2 \%$ sodium thiosulfate solution for $5 \mathrm{~min}$. After rinsing twice with water, the samples were dehydrated and mounted using Eukitt (Kindler).

\section{Electron microscopic analysis}

The optic and sciatic nerves of male and female Cnp1-Cre;fl/fl and control mice, respectively, as well as the sciatic nerve of male Plp1-CreERT2; $f l / f l$ and control mice were dissected and postfixed in Karlsson-Schulz fixative. The tissue was embedded in Epon according to a modified method described by Luft (1961). Staining of semithin sections: The embedded samples were sectioned using a microtome (Ultracut $S$, Leica Microsystems) while cutting with a diamond knife (Diatome Ultra $45^{\circ}$ ) semithin section of $500 \mathrm{~nm}$ thickness. The semithin sections were stained using methylene blue and Azure II staining solution (1:1) for $1 \mathrm{~min}$ at $60^{\circ} \mathrm{C}$. Semithin sections were observed under a light microscope. Contrasting of ultrathin sections: $50 \mathrm{~nm}$ ultrathin sections were cut. The samples were placed onto formvar-polyvinyl-coated cupper grids (2 mm-1 mm, Agar Scientific) and contrasted with a $1 \%$ uranyl acetate solution and Reynolds lead citrate (Reynolds, 1963). Images were taken with the CM10 electron microscope by Philips combined with a wideangle dual-speed $2 \mathrm{~K}$-CCD camera Veleta by Olympus. ImageJ, Microsoft Excel, and GraphPad Prism were used for further analyses. For g-ratio measurement, 100 axons of 10 images (3000× magnification) per animal were analyzed in a blinded manner using ImageJ. The g-ratio is defined by the inner to the outer diameter of the myelin sheath. The g-ratio was determined by measuring the outer circumference of the myelin sheath, as well as the inner circumference $(c)$ from which the respective diameter (d) was derived $(d=c / \pi)$. A baseline g-ratio value is $\sim 0.77$ in the CNS and 0.6 in the PNS. Higher values indicate hypomyelination, whereas smaller values indicate hypermyelination. For analyses, electron micrographs were blinded and pathological abnormalities were assessed.

\section{Plasmids and antibodies}

For generating short hairpin RNA, the pSUPER RNAi System was used. Target sequences against homologous sequences of human, mouse, and rat were used: Fbxo7 shRNA \#1 (functional): $5^{\prime}$-gaagagaccttggcttcata-3'; and Fbxo7 shRNA ctrl (nonfunctional): 5' -gaaactacgcatcttccgac- $3^{\prime}$.

Antibodies used for immunoblot analysis included the following: $\mathrm{ms}$ $\alpha$-pan 14-3-3 (Santa Cruz Biotechnology, sc-1657, 1:1000 dilution), ms $\alpha$-FBXO7 (Santa Cruz Biotechnology, sc-271763, 1:50 dilution), ms $\alpha$-glutathione S-transferase $\pi 1$ (GST $\pi 1$ ) (BD Biosciences, 610719, 1:250 dilution), ms $\alpha$-NF-M (Santa Cruz Biotechnology, sc-51683, 1:200 dilution), ms $\alpha$-PLP (kindly provided by Prof. Dr. Mikael Simons, 1:50 dilution), ms $\alpha$-Sox10 (Santa Cruz Biotechnology, sc-365692, 1:200 dilution), and HRP-coupled secondary goat $\alpha$-mouse IgG (Dianova, 113-035-146, 1:10,000 dilution).

Antibodies used for immunohistochemistry are as follows: ms $\alpha$-APP 6E10 (Biolegend, 803004, 1:200 dilution), ms $\alpha$-GFAP (Nova Castra, NCL-GFAP-GA5, 1:200), ms $\alpha$-GST $\pi 1$ (BD Biosciences, 610719, 1:200 dilution), $\mathrm{rb} \alpha$-Iba1 (Wako, 019-19741, 1:1000 dilution), rb $\alpha$-MBP (Cell Signaling Technology, 78896T, 1:200 dilution), ms $\alpha$-PLP (kindly provided by Prof. Dr. Mikael Simons, 1:000 dilution), Cy3/Alexa-555 coupled secondary antibodies goat $\alpha$-mouse IgG and goat $\alpha$-rabbit IgG (Dianova, 1:1000 dilution), and Cy2/Alexa 488 coupled secondary antibodies goat $\alpha$-mouse IgG and goat $\alpha$-rabbit IgG (Dianova, 1:1000 dilution).

\section{$q R T-P C R$}

To measure the relative expression of different mRNA levels, first RNA was isolated from male Cnp-Cre; fl/fl and control cerebella using the TRIZOL reagent (Invitrogen). The respective cDNA was synthesized using the SuperScript III First-strand Synthesis System (Invitrogen). A qRTPCR was performed using the Power SYBR Green system and PCR thermo cycler (Thermo Fischer Scientific). Microsoft Excel was used for analysis, applying the Livak- $\delta$ - $\delta \mathrm{C}_{\mathrm{T}}$ method for quantification. $\beta$-Actin was used as a reference gene, in addition to the average of all control samples. The following primers were used for qRT-PCR: IL-10 (forward): $5^{\prime}$-atgcaggactttaagggttacttg- $3^{\prime}$, (reverse): $5^{\prime}$-tagacaccttggtcttgg agctta- $3^{\prime}$; IL-1RA (forward): $5^{\prime}$-cagttccaccctgggaaggt- $3^{\prime}$, (reverse): $5^{\prime}$ gagcggatgaaggtaaagcg- $3^{\prime}$; IL- $1 \beta$ (forward): $5^{\prime}$-cctgcagctggagagtgtgga- $3^{\prime}$, (reverse): $5^{\prime}$-cccatcagaggcaaggaggaa- $3^{\prime}$; IL-6 (forward): $5^{\prime}$-cggagagg agacttcacagagga- $3^{\prime}$, (reverse): $5^{\prime}$-ggagagcattggaaattgggg- $3^{\prime}$; Tnf- $\alpha$ (forward): $5^{\prime}$-gcggtgcctatgtctcagcc- $3^{\prime}$, (reverse): $5^{\prime}$-tgaggagcacgtagtcgggg$3^{\prime}$; Ip-10 (forward): 5' -ctgcctcatcctgctgggtctg- $3^{\prime}$, (reverse): $5^{\prime}$-ataggctcg cagggatgatttcaagc- $3^{\prime}$; Mcp1 (forward): $5^{\prime}$-ggtccctgtcatgcttctgggc- $3^{\prime}$, (reverse): $5^{\prime}$-agcaggtgtcccaaagaagctgtagt- $3^{\prime} ; \beta$-actin (forward): $5^{\prime}$-cgtg cgtgacatcaaagagaagctg- $3^{\prime}$, (reverse): $5^{\prime}$-ggatgccacaggattccatacccaag- $3^{\prime}$; Fbxo7 (forward): $5^{\prime}$-tggaagtcaagtggtgtatac-3', (reverse): $5^{\prime}$-tactccagca gcaacgtagga- $3^{\prime}$.

\section{Transduction of MSC80 cell line}

To generate a stable cell line expression of the Fbxo7 shRNAs, an adenoassociated viral transduction was performed. HEK293T cells were transfected with the pLentiLox 3.7 system ( $p$ ll3.7/fbxo7 puro, pVSVG, pREVREV, and pRRE), (Rubinson et al., 2003). Three days after transfection, the supernatant, containing lentiviral particles, was collected and added to cultured MSC80 cells for transduction. Transduced MSC80 cells were treated with $0.75 \mu \mathrm{g} / \mathrm{ml}$ puromycin for selection. Cells resistant to puromycin incorporated the construct of interest and showed a stable expression of the Fbxo7 shRNAs. These cells were cultured and passaged like normal immortalized cell lines.

\section{Primary cell culture}

Primary Schwann cell and cerebellar granule neurons (CGNs) were cultured from male and female postnatal day 5 (P5) mouse sciatic nerves 
and brachial plexus or cerebella as previously described (Dong et al., 1999; Holubowska et al., 2014).

\section{Proteasome activity assay}

The proteasome activity assay was performed as described by Kisselev and Goldberg (2005). The assay was performed with lysates of transduced MSC80 cells, primary Schwann cells, and primary CGNs. Cells were lysed in proteasome lysis buffer (50 mM Tris- $\mathrm{HCl}, \mathrm{pH}$ 7.5, $250 \mathrm{~mm}$ sucrose, $5 \mathrm{~mm} \mathrm{MgCl}_{2}$, 0.5 mм EDTA, 2 mм ATP, 1 mм DTT, 0.025\% digitonin); $100 \mu \mathrm{g}$ BSA and $100 \mu \mathrm{M}$ of fluorogenic peptide substrate Suc-LLVY-AMC were added to the proteasome assay buffer $(50 \mathrm{~mm}$ Tris-HCl, pH 7.5, 40 mm KCl, 5 mm $\mathrm{MgCl}_{2}, 0.5$ mм ATP, 1 mм DTT) and were incubated for $10 \mathrm{~min}$ at $37^{\circ} \mathrm{C} ; 12 \mu \mathrm{g}$ of cell lysate was added per well. The fluorescent signal was measured at $355 / 460 \mathrm{~nm}$ and at $0,30,60,90$, and 120 min using the Tecan microplate reader. To verify the reduction of FBXO7 induced by shRNA or FBXO7 KO, part of the cell lysate was set aside and subjected to Western blot analysis.

\section{Myelin purification}

Myelin was purified from female brain samples by density centrifugation using a sucrose gradient. According to Norton and Poduslo's previously described method (Norton and Poduslo, 1973; Larocca and Norton, 2007), the samples were homogenized in $0.32 \mathrm{M}$ sucrose containing protease inhibitors and using the ULTRA-TURRAX (IKA). The homogenate was carefully pipetted onto $0.85 \mathrm{M}$ sucrose, supplemented with protease inhibitors, and transferred in an Ultra-Clear Tube (Beckman, \#344060). The sucrose gradient was centrifuged for $30 \mathrm{~min}$ at 75,000 $\times \mathrm{g}$ in the Beckman XL-70 ultracentrifuge, using a swingout rotor (SW40Ti Beckman rotor, 24,400 rpm). The interphase was transferred into a new tube and washed with water. After centrifugation at $75,000 \times g$ for $15 \mathrm{~min}$, an osmotic shock was induced by resuspending the pellet in $\mathrm{H}_{2} \mathrm{O}$, incubated for $15 \mathrm{~min}$, and centrifuged at 12,000 $\times \mathrm{g}$ for $15 \mathrm{~min}$ (SW40Ti Beckman rotor, $9700 \mathrm{rpm}$ ). This osmotic shock procedure was repeated once. Subsequently, the pellet was resuspended in $0.32 \mathrm{~m}$ sucrose and transferred onto $0.85 \mathrm{~m}$ sucrose layer, which represents the second sucrose gradient. After centrifugation for $30 \mathrm{~min}$ at $75,000 \times \mathrm{g}$, the interphase was collected in a new tube, $\mathrm{H}_{2} \mathrm{O}$ was added and centrifuged at 75,000 $\times$ $g$ for $15 \mathrm{~min}$. This final pellet consisted of enriched myelin and was resuspended in $200 \mu \mathrm{l}$ of TBS containing protease inhibitors and was stored at $-80^{\circ} \mathrm{C}$.

For myelin purification, sciatic nerve isolated from male and female animals was homogenized in $0.29 \mathrm{M}$ sucrose containing protease inhibitors using an ULTRA-TURRAX (IKA). The lysate was added onto $0.85 \mathrm{M}$ sucrose in an Ultra-Clear Tube (Beckman, \#344062). The samples were centrifuged for $30 \mathrm{~min}$ at $75,000 \times g(26,900 \mathrm{rpm})$ in a TH660 Beckman rotor. The interphase was washed with water as described before, and only one osmotic shock procedure was performed. The pellet was resuspended in $100 \mu \mathrm{l}$ of TBS containing protease inhibitors and stored at $-80^{\circ} \mathrm{C}$.

\section{Label-free quantitative mass spectrometry}

Protein quantification. Proteolytic digestion. Protein fractions corresponding to $10 \mu \mathrm{g}$ myelin protein were processed according to a filteraided sample preparation protocol modified essentially as described by Distler et al. $(2014,2016)$. Myelin protein samples were lysed and reduced in lysis buffer ( $7 \mathrm{~m}$ urea, $2 \mathrm{~m}$ thiourea, 10 mм DTT, $0.1 \mathrm{~m}$ Tris, pH 8.5 ) containing $1 \%$ ASB- 14 by shaking for $30 \mathrm{~min}$ at $37^{\circ} \mathrm{C}$. Subsequently, the sample was diluted with 10 volumes lysis buffer containing $2 \%$ CHAPS to reduce the ASB-14 concentration and loaded on centrifugal filter units (30 kDa MWCO, Millipore). Unless stated otherwise, all steps were automated on a liquid-handling workstation equipped with a vacuum manifold (Freedom EVO 150, Tecan) by using an adaptor device constructed in-house. After removal of the detergents by washing twice with wash buffer ( $8 \mathrm{M}$ urea, $10 \mathrm{~mm}$ DTT, $0.1 \mathrm{M}$ Tris, $\mathrm{pH} 8.5$ ), proteins were alkylated with $50 \mathrm{~mm}$ iodoacetamide in $8 \mathrm{~m}$ urea/0.1 M Tris, pH 8.5 (20 min at room temperature), followed by two washes with wash buffer to remove excess reagent. Buffer was exchanged by washing three times with $50 \mathrm{~mm}$ ammonium bicarbonate $(\mathrm{ABC})$ containing $10 \%$ acetonitrile. After three additional washes with $50 \mathrm{~mm} \mathrm{ABC/10 \%}$ acetonitrile, which were performed by centrifugation to ensure quantitative removal of liquids, proteins were digested overnight at $37^{\circ} \mathrm{C}$ with $500 \mathrm{ng}$ trypsin in 40 $\mu l$ of the same buffer. Tryptic peptides were recovered by centrifugation followed by two additional extraction steps with $40 \mu \mathrm{l}$ of $50 \mathrm{~mm} \mathrm{ABC}$ and $40 \mu \mathrm{l}$ of $1 \%$ trifluoroacetic acid, respectively. Aliquots of the combined flow-throughs were spiked with $10 \mathrm{fmol} / \mu$ l of yeast enolase 1 tryptic digest standard (Waters) for quantification purposes (Silva et al., 2006) and directly subjected to analysis by liquid chromatography coupled to electrospray mass spectrometry (LC-MS).

LC-MS analysis. Nanoscale reversed-phase UPLC separation of tryptic peptides was performed with a nanoAcquity UPLC system equipped with a Symmetry C18 $5 \mu \mathrm{m}, 180 \mu \mathrm{m} \times 20 \mathrm{~mm}$ trap column and an HSS T3 $\mathrm{C} 181.8 \mu \mathrm{m}, 75 \mu \mathrm{m} \times 250 \mathrm{~mm}$ analytical column maintained at $45^{\circ} \mathrm{C}$ (Waters). Injected peptides were trapped for $4 \mathrm{~min}$ at a flow rate of 8 $\mu \mathrm{l} / \mathrm{min} 0.1 \%$ trifluoroacetic acid and then separated over $120 \mathrm{~min}$ at a flow rate of $300 \mathrm{nl} / \mathrm{min}$ with a gradient comprising two linear steps of 3\%-35\% mobile Phase B in $105 \mathrm{~min}$ and 35\%-60\% mobile Phase B in 15 min, respectively. Mobile Phase A was water containing $0.1 \%$ formic acid, whereas mobile Phase B was acetonitrile containing $0.1 \%$ formic acid. Mass spectrometric analysis of tryptic peptides was performed using a Synapt G2-S quadruple time-of-flight mass spectrometer equipped with ion mobility option (Waters). Positive ions in the mass range $\mathrm{m} / \mathrm{z}$ 50-2000 were acquired with a typical resolution of at least 20,000 FWHM, and data were lock mass corrected after acquisition. Analyses were performed in the ion mobility-enhanced data-independent acquisition mode drift time-specific collision energies as described in detail by Distler et al. (2014, 2016). Specifically, a novel data acquisition strategy with dynamic range enhancement was used, in which a deflection lens cycles between full and reduced ion transmission during one scan. This method provides an optimal trade-off between identification rate (i.e., proteome depth) and dynamic range for correct quantification of highabundant myelin proteins. Continuum LC-MS data were processed for signal detection, peak picking, and isotope and charge state deconvolution using Waters ProteinLynx Global Server (PLGS) version 3.0.2 (Li et al., 2009). For protein identification, a custom database was compiled by adding the sequence information for yeast enolase 1 and porcine trypsin to the UniProtKB/Swiss-Prot mouse proteome and by appending the reversed sequence of each entry to enable the determination of false discovery rate (FDR). Precursor and fragment ion mass tolerances were automatically determined by PLGS 3.0.2 and were typically $<5 \mathrm{ppm}$ for precursor ions and $<10 \mathrm{ppm}$ (root mean square) for fragment ions. Carbamidomethylation of cysteine was specified as fixed and oxidation of methionine as variable modification. One missed trypsin cleavage was allowed. Minimal ion matching requirements were two fragments per peptide, five fragments per protein, and one peptide per protein. The FDR for protein identification was set to $1 \%$ threshold.

Experimental design and data analysis. Myelin was purified from the CNS and PNS of Cnp1-Cre; fl/fl and control mice. Myelin protein fractions from the CNS of 5 animals per condition (Ctrl, KO) and from the PNS of 9 animals per condition, each pooled into 3 samples, were processed with replicate digestion, resulting in two technical replicates per biological replicate and thus in a total of 20 (CNS)/12 (PNS) LC-MS runs to be compared, respectively. The freely available software ISOQuant (http://www.isoquant.net) was used for postidentification analysis, including retention time alignment, exact mass and retention time, and ion mobility clustering, data normalization, isoform/homology filtering, and calculation of absolute in-sample amounts for each detected protein according to the TOP3 quantification approach (Distler et al., 2014, 2016; Kuharev et al., 2015). Only peptides with a minimum length of seven amino acids, which were identified with PLGS scores $\geq 5.5$ in at least two runs, were considered. FDR for both peptides and proteins was set to $1 \%$ threshold, and only proteins reported by at least two peptides were quantified using the TOP3 method. The parts per million (ppm) abundance values, that is, the relative amount $(\mathrm{w} / \mathrm{w})$ of each protein in respect to the sum over all detected proteins, were log2-transformed and normalized by subtraction of the median derived from all data points for the given protein. Significant changes in protein abundance were detected by moderated $t$ statistics with an empirical Bayes approach and FDR-based correction for multiple comparisons (Kammers et al., 2015). For this purpose, the Bioconductor packages "limma" (Ritchie et al., 2015) and " $q$ value" (Storey and Tibshirani, 2003) were used in RStudio, an inte- 

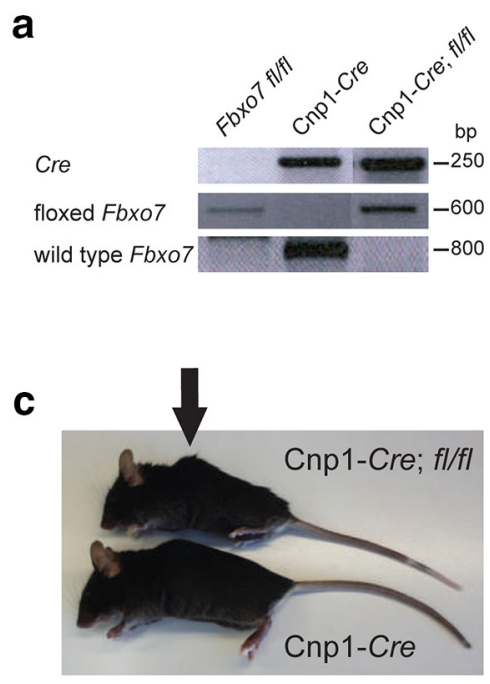

b

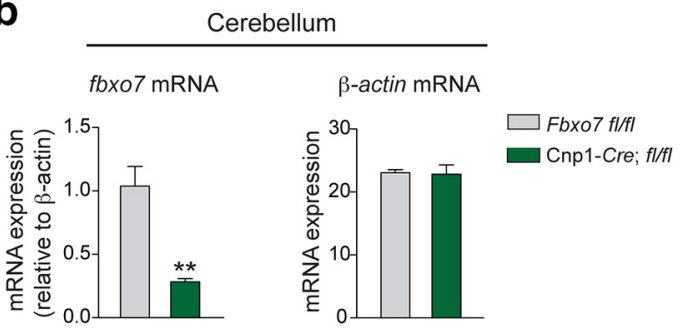

d

Weight

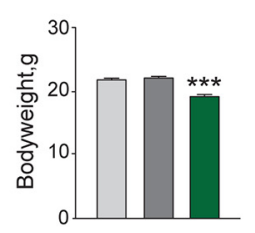

e

Hind limb clasping

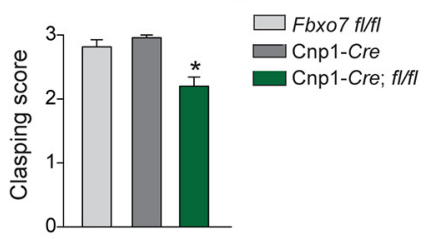

f

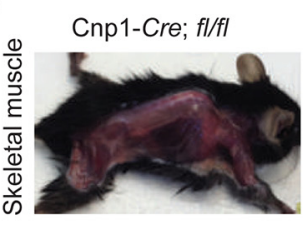

h Inverted grid

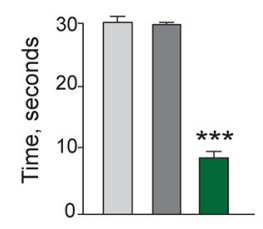

k

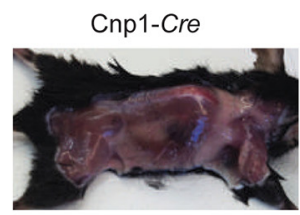

i

(1) g

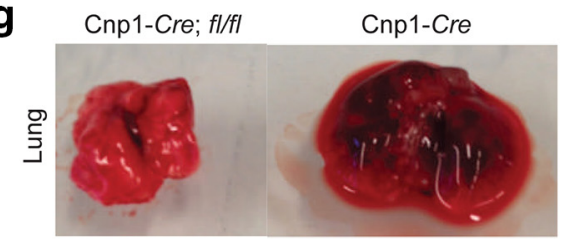

j

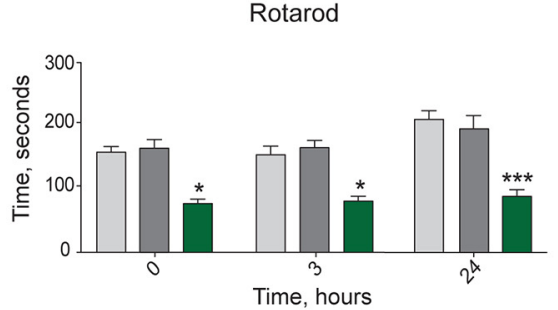

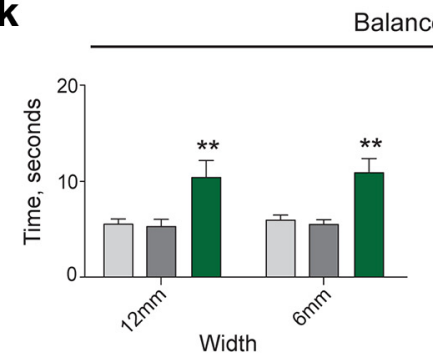

Balance beam

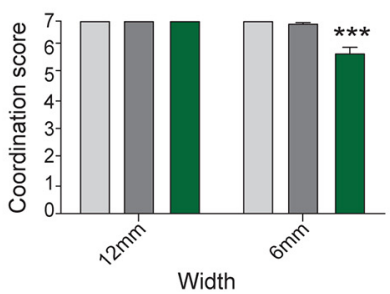

Figure 1. Loss of $F b \times 07$ in myelinating cells triggers motor impairment together with organic pathologies. a, Genotyping PCR of control (Fbxo7fl/fl, Cnp1-Cre) and conditional K0 mice (Cnp1-Cre;flffl).b, qRT-PCR of fbxo7 and $\beta$-actin in cerebella isolated from 2-month-old, male Fbxo7fl/fland Cnp1-Cre;fl/fl mice; 4 animals per genotype were included in the analysis. ${ }^{* *} p=0.0029$ (Student's unpaired $t$ test). Data are mean \pm SEM. c, Representative images of 2-month-old, male control and Cnp1-Cre;fl/fl mice. Arrow indicates kyphosis. $\boldsymbol{d}$, Average weight of 8 male Fbxo7fl/fl, 9 Cnp1-Cre, and 10 Cnp1-Cre;fl/fl mice. ${ }^{* * *} p<0.001$ (one-way ANOVA, Bonferroni test). Data are mean \pm SEM. e, 8 Fbxo7fl/fl, 9 Cnp1-Cre, and 10 Cnp1-Cre;fl/fl mice (all male) were subjected to hindlimb clasping test. ${ }^{*} p<0.05$ (Kruskal-Wallis test, Dunn'stest). Data are mean \pm SEM. $\boldsymbol{f}$, Exposed skeletal muscles of 3-month-old, male Cnp1-Cre;fl/fland control mouse (Cnp1-Cre). $\boldsymbol{g}$, Isolated

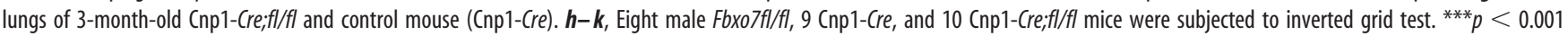
(Kruskal-Wallis test, Dunn's test). Data are mean \pm SEM. $\boldsymbol{h}$, Open field test. ${ }^{*} p<0.05$ (one-way ANOVA, Bonferroni test). Data are mean \pm SEM. $\boldsymbol{i}$, Rotarod test. ${ }^{*} p<0.05$ (two-way ANOVA, Bonferroni test). ${ }^{* * *} p<0.001$ (two-way ANOVA, Bonferroni test). Data are mean \pm SEM. $j$, Balance beam test. ${ }^{* *} p<0.01$ (two-way ANOVA, Bonferroni test). ${ }^{* * *} p<0.001$ (two-way ANOVA, Bonferroni test). $\boldsymbol{k}$, Data are mean \pm SEM.

grated development environment for the open source programming language R. Detected proteins were displayed in a volcano plot, highlighting those candidates that showed a significance of $q<0.01$ and a $25 \%$ upregulation and downregulation compared with control.

ImageJ and Microsoft Excel were used to quantify data. For statistical analyses, GraphPad Prism was used. Depending on the experimental designs and requirements, Student's unpaired $t$ test; one- or two-way
ANOVA, followed by Bonferroni test multiple comparison test; KruskalWallis, followed by Dunn's multiple comparison test, or $\chi^{2}$ test was applied. Statistical differences were considered significant if $p<0.05$. Whenever possible, the exact $p$ value was indicated. All data were displayed as SEM. Each figure legend contains elaborate information on experiments (gender, number of animals or independent experiments included in the analyses, statistics, $p$ values). 
a

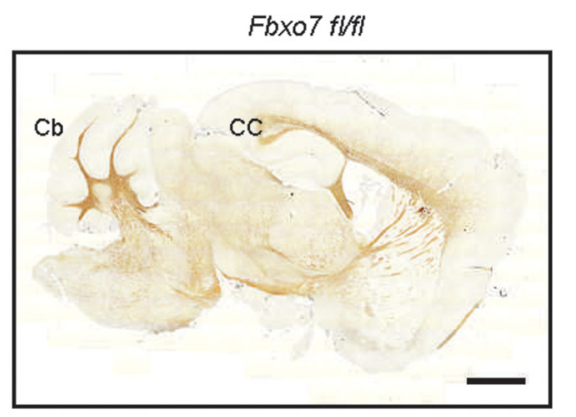

Cnp1-Cre; flff

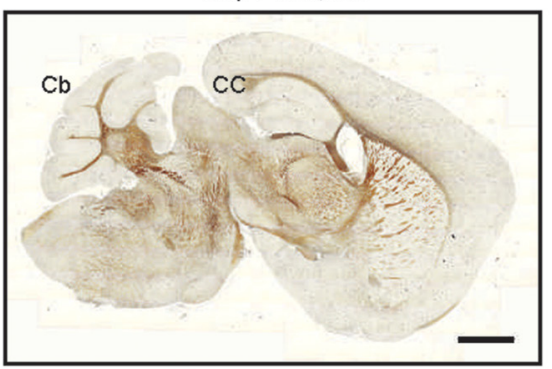

b
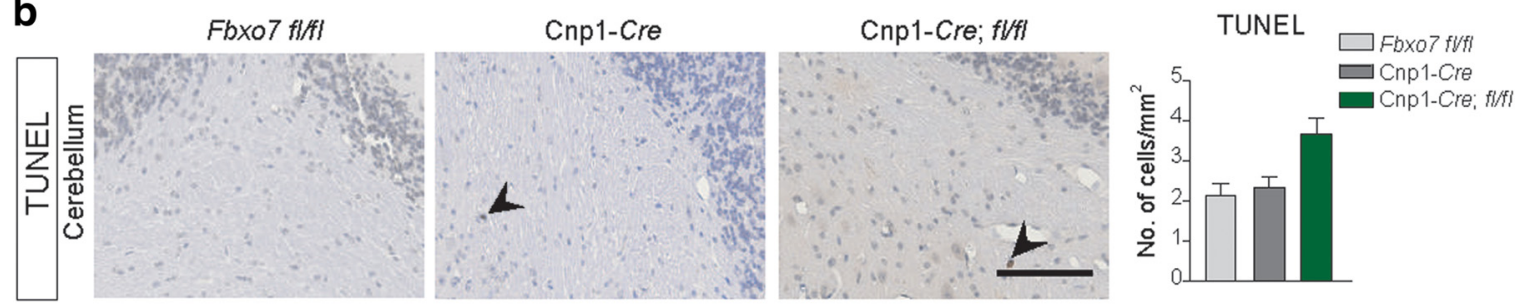

C

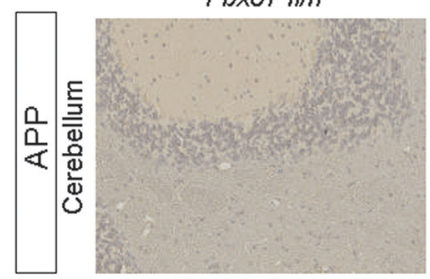

d

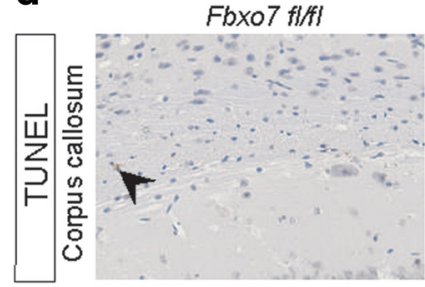

e

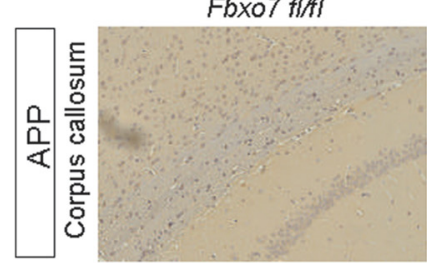

Cnp1-Cre; flffl

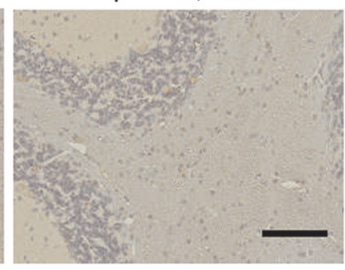

Cnp1-Cre
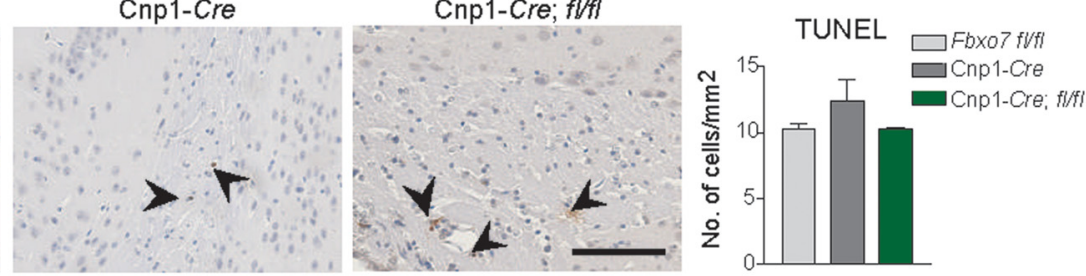

Figure 2. Histological analyses of the CNS of Cnp1-Creffl/fl mice. $\boldsymbol{a}$, Sagittal brain sections of male control and conditional K0 mice were subjected to Gallyas' silver impregnation of myelin. Cb, Cerebellum; CC, corpus callosum. Scale bar, $0.5 \mathrm{~mm}$. b, c, Sagittal cerebellar sections of 3-month-old, male control mice (Fbxo7fl/fl or Cnp1-Cre) and (nnp1-Cre;fl/fl mice were subjected to TUNEL staining (arrowheads); 3 animals per genotype were included in the analysis. Data are mean \pm SEM (b) or immunostaining with the APP antibody (c). Scale bar, $100 \mu$ m. $\boldsymbol{d}, \boldsymbol{e}$, Sagittal forebrain sections of 3-month-old, male control mice and (np1-Cre,fl/fl mice were subjected to TUNEL staining (arrowheads); 3 animals per genotype were included in the analysis. Data are mean \pm SEM (d) or immunostaining with the APP antibody (e). Scale bar, $100 \mu \mathrm{m}$. 
a
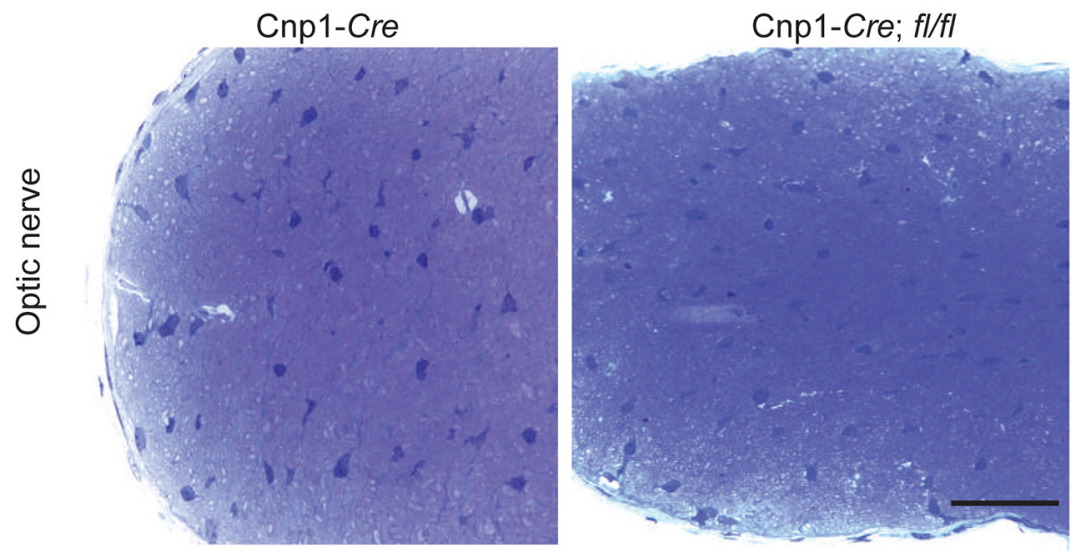

b
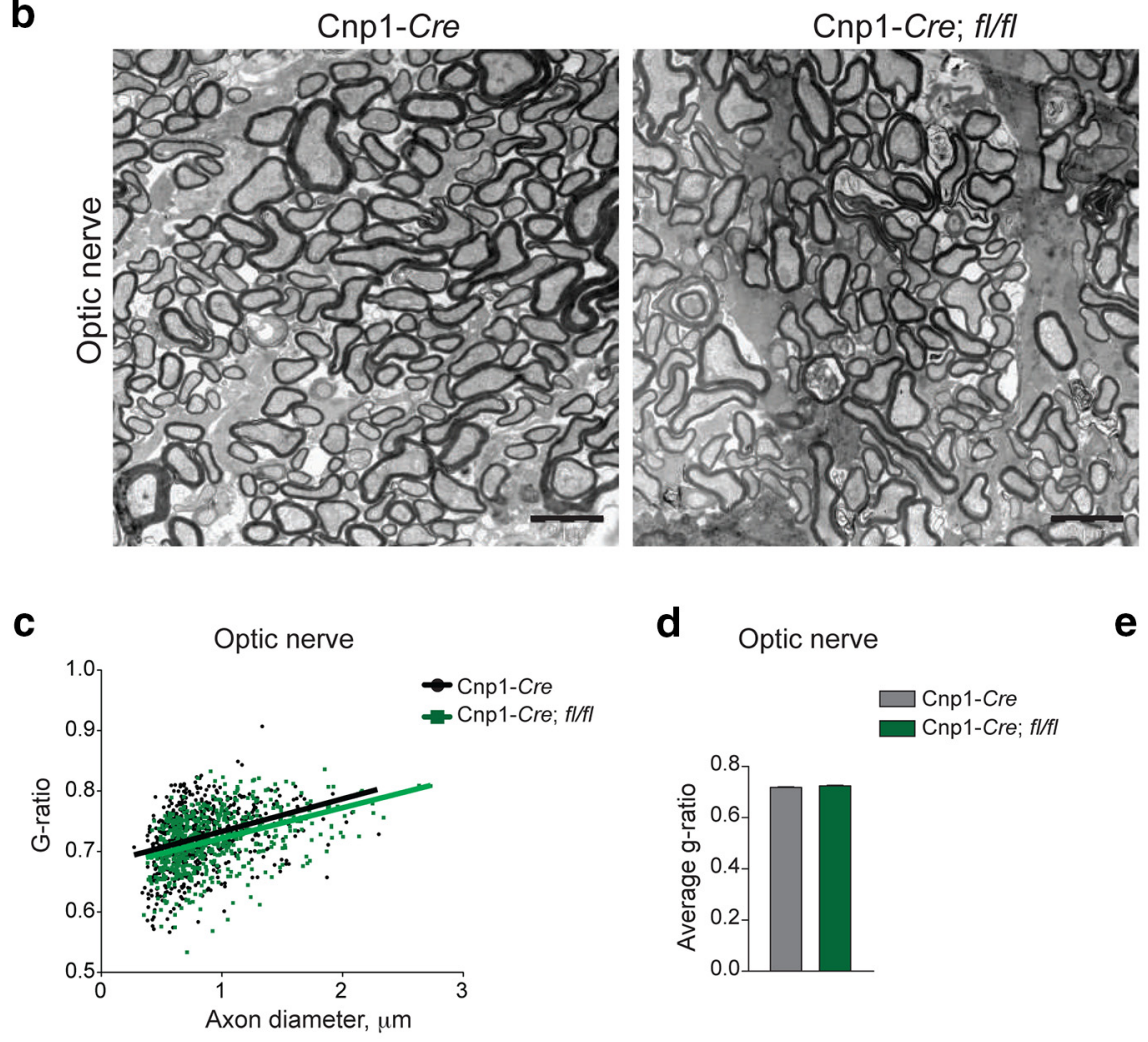

d

Optic nerve

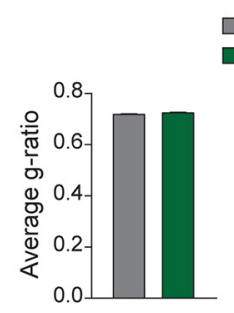

f

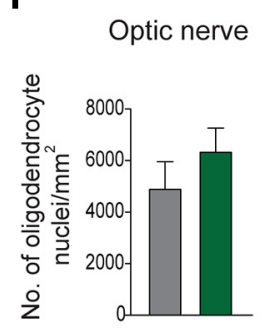

g

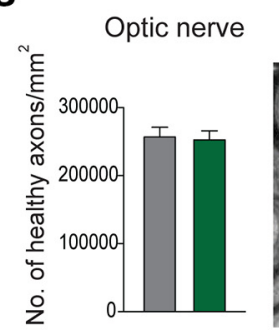

e

Distribution of axon diameter in optic nerve

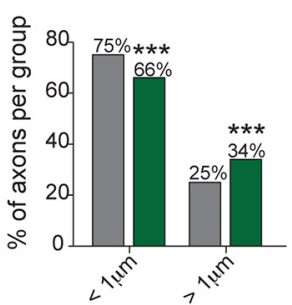

Cnp1-Cre

Cnp1-Cre; fl/fl

\section{h}

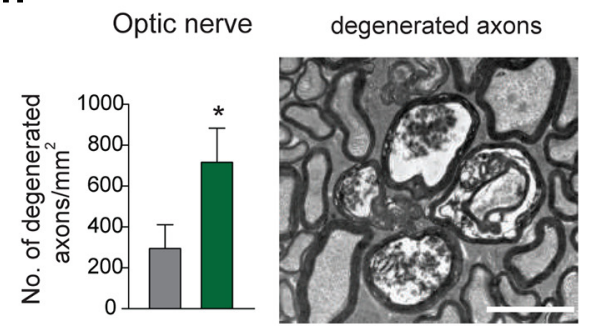

Figure 3. Effects of Fbxo7 deletion on myelination in the CNS. $\boldsymbol{a}$, Semithin section of control and KO optic nerve. Scale bar, $20 \mu \mathrm{m} . \boldsymbol{b}$, Representative electron micrographs of cross sections of optic nerve of control (Cnp1-Cre) and Cnp1-Cre,fl/fl mice. Scale bar, $2 \mu \mathrm{m} . \boldsymbol{c}, \boldsymbol{d}, 0$ ptic nerves isolated from control and Cnp1-Cre;fl/fl mice were subjected to electron microscopy analysis. Three male animals per genotype and 200 axons per mouse were included in the g-ratio measurements displayed in scatter plot (c) and as average values (d). Data are mean \pm SEM. $\boldsymbol{e}$, Distribution of axon caliber in optic nerve of control and (np1-Cre,fl/fl mice. The percentage of axons per group was analyzed. ${ }^{* * *} p<0.001\left(\chi^{2}\right.$ test). $\boldsymbol{f}-\boldsymbol{h}$, Average number of oligodendrocyte nuclei/mm ${ }^{2}$. Student's unpaired $t$ test. Data are mean \pm SEM. $\boldsymbol{f}$, Axons $/ \mathrm{mm}^{2}$.Student's unpaired $t$ test. Data are mean \pm SEM $(\boldsymbol{g})$ and degenerated axons $/ \mathrm{mm}^{2}{ }^{*} p=0.0437$ (Student's unpaired $t$ test). Data are mean \pm SEM. $\boldsymbol{h}$, Representative electron micrographs of healthy and degenerated axons. Scale bars: $\boldsymbol{g}, 0.5 \mu \mathrm{m} ; \boldsymbol{h}, 2 \mu \mathrm{m}$. 
a

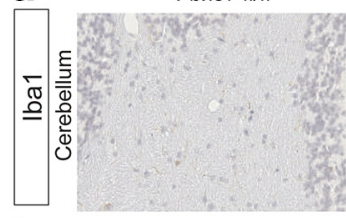

b

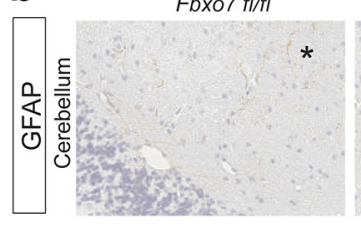

C

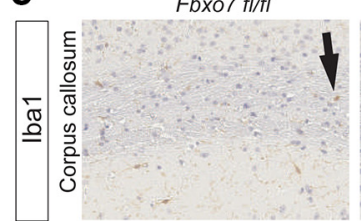

d $F b \times 07 f|/ f|$

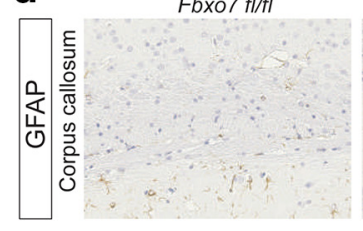

e

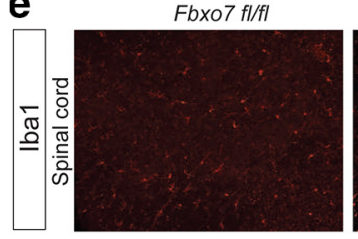

f

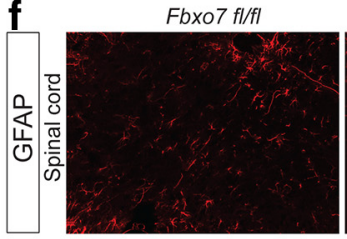

Cnp1-Cre

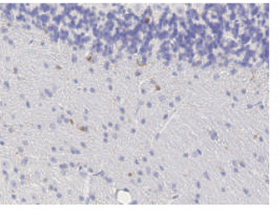

Cnp1-Cre

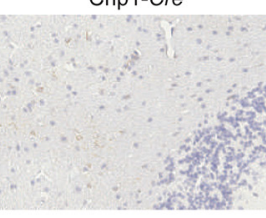

Cnp1-Cre

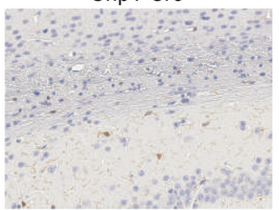

Cnp1-Cre

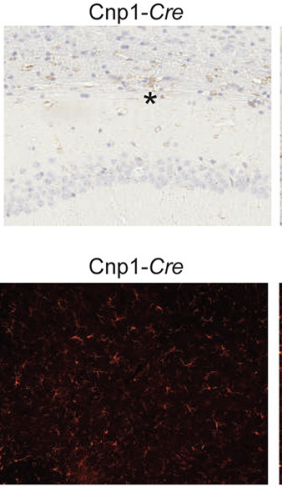

Cnp1-Cre

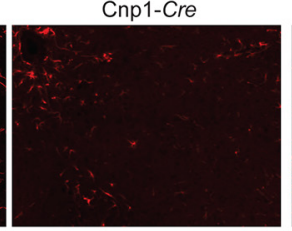

Cnp1-Cre; fl/fI

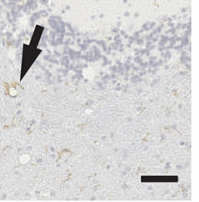

Cnp1-Cre; fl/fl

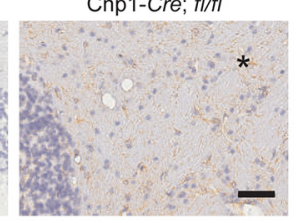

Cnp1-Cre; fl/fI
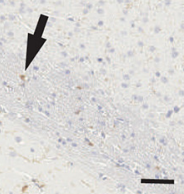

Cnp1-Cre; fl/fl

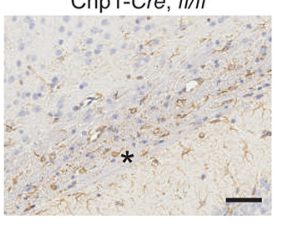

Cnp1-Cre; fl/fl

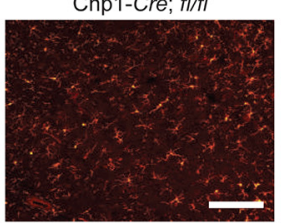

Cnp1-Cre; fl/fI

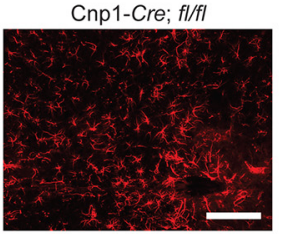

Iba1
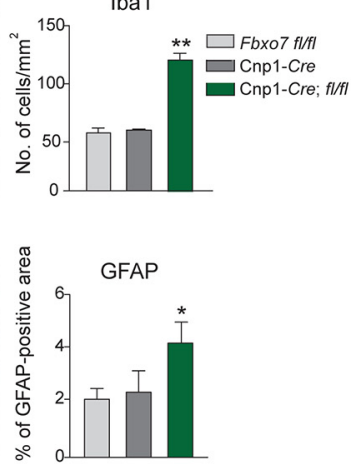

Iba1
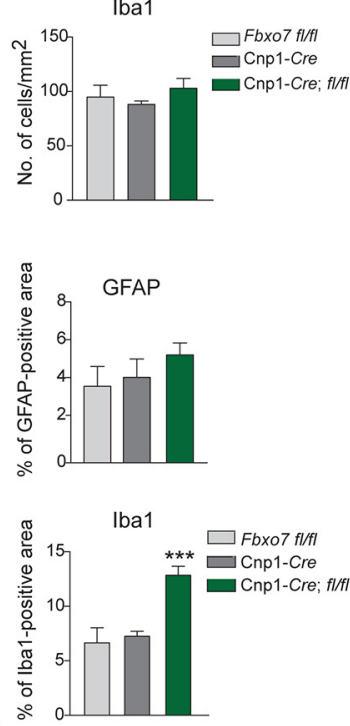

g

anti-inflammatory markers

Cerebellum

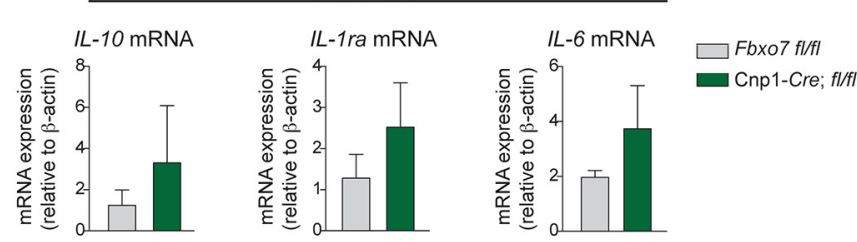

h

pro-inflammatory markers

Cerebellum
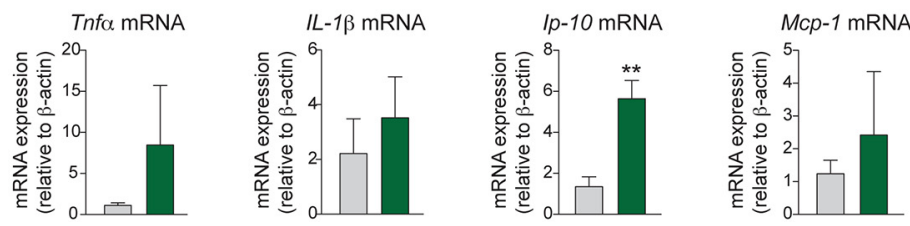

Figure 4. Pathological changes in the CNS white matter upon Fbxo7 deletion. $\boldsymbol{a}, \boldsymbol{b}$, Sagittal cerebellar sections of 3-month-old, male Fbxo7fl/fl, Cnp1-Cre and Cnp1-Cre;fl/fl mice were subjected to immunostaining with the lba1 or GFAP antibodies (arrow indicates Iba ${ }^{+}{ }^{+}$cell; asterisks indicate GFAP ${ }^{+}$cells); 3 animals per genotype were included in the analysis. ${ }^{*} p<0.05$ (one-way ANOVA, Bonferroni test). ${ }^{* *} p<0.01$ (one-way ANOVA, Bonferroni test). Data are mean \pm SEM. Scale bar, $50 \mu \mathrm{m}$. c, d, Sagittal forebrain sections of 3-month-old, male control and Cnp1-Cre;fl/fI mice were subjected to immunostaining with the Iba1 (arrows indicate Iba ${ }^{+}$cells) or GFAP antibodies (asterisks indicate GFAP ${ }^{+}$cells); 3 animals per genotype were included in the (Figure legend continues.) 


\section{Results}

In our previous study (Vingill et al., 2016), we generated a reporter mouse line, in which the lacZ cassette was controlled by the endogenous $\mathrm{FBXO} 7$ promoter. $\beta$-Galactosidase expression revealed a prominent expression of FBXO7 in the corpus callosum and in the cerebellar white matter. To examine the functional relevance of FBXO7 in myelinating cells in vivo, we mated $\mathrm{Fbxo} 7 \mathrm{fl} / \mathrm{fl}$ mice with the Cnp1-Cre driver line (Lappe-Siefke et al., 2003) to delete $\mathrm{Fbxo} 7$ in predominantly myelinating cells of the CNS and PNS.

Genotyping of these animals revealed living conditional $\mathrm{KO}$ mice at the time of weaning (Fig. 1a). A reduction in mRNA was clearly detectable in cerebellar tissue with large areas of white matter (Fig. 1b). At 6 weeks of age, the conditional $\mathrm{KO}$ mice (Cnp1-Cre;Fbxo7fl/fl, short: Cnp1-Cre;fl/fl) were visibly different from control mice (Cnp1-Cre). The mice were characterized by kyphosis (Fig. 1c), reduced weight (Fig. 1d), and a slightly reduced hindlimb clasping score (Fig. 1e). At 4 months of age, the $\mathrm{KO}$ mice deteriorated quickly as the hindlimb weakness progressed to a more severe hindlimb paresis. Autopsies revealed atrophy of the muscles in the hind limbs (Fig. $1 f$ ) and atrophic lungs (Fig. $1 g$ ). The mice also became very emaciated and had to be killed.

To characterize the motor phenotype, we subjected 6-weekold Cnp1-Cre;fl/fl and control mice to motor tests and found that KO mice were significantly impaired in holding on to an inverted grid compared with control groups ( $\mathrm{Fbxo} 7 \mathrm{fl} / \mathrm{fl}$ or Cnp1-Cre) (Fig. $1 h)$. In addition, the track length of the KO mice in the open field arena was significantly reduced compared with control groups (Fig. 1i). We also analyzed the motor learning and coordination using the rotarod and the balance beam, respectively. We found that Cnp1-Cre;fl/fl mice were unable to improve their performance on the rotarod (Fig. 1j) and lacked the proper motor coordination to keep up with control mice on the balance beam both with respect to the time and the coordination while traversing the beam (Fig. $1 k$ ). These results demonstrate that loss of Fbxo7 in myelinating cells negatively affects the overall morphology and posture of the mice in addition to their motor performance.

To investigate whether deletion of $\mathrm{Fbxo} 7$ has any effects on myelination in the CNS and PNS in 3-month-old mice, we first examined whether there are any gross morphological changes in the myelinated regions in the brain upon Gallyas staining, but we did not detect any obvious difference in the pattern of the tracts (Fig. 2a). In addition, we did not observe an increase in TUNEL ${ }^{+}$ or $\mathrm{APP}^{+}$cells in the white matter of the cerebellum or the corpus callosum, indicating no cell death or axonal impairment in white matter areas at the time of analysis (Fig. $2 b-e$ ).

Next, we turned to a more in-depth histological analysis of the CNS and performed electron microscopy of the optic nerve of control (Cnp1-Cre) and Cnp1-Cre;fl/fl mice. We first examined semithin sections of the nerve, which did not reveal any gross morphological changes (Fig. 3a). Using higher-magnification

\section{$\leftarrow$}

(Figure legend continued.) analysis. Data are mean \pm SEM. Scale bar, $50 \mu \mathrm{m} . \boldsymbol{e}, \boldsymbol{f}$, Cross sections of the spinal cord (approximately lumbar region L3-L5) isolated from male and female control and Cnp1-Cre,fl/fl mice were immunostained with the Iba1 or GFAP antibodies; 3 animals per genotype were included in the analysis. ${ }^{* *} p<0.001$ (one-way ANOVA, Bonferroni test). Data are mean \pm SEM. Scale bar, $50 \mu \mathrm{m} . \boldsymbol{g}, \boldsymbol{h}, \mathrm{RT}-\mathrm{PCR}$ analysis of anti-inflammatory and proinflammatory cytokines in the cerebellar white matter of male control and Cnp1-Cre;fl/fl mice; 4 animals per genotype were included in the analysis. ${ }^{* *} p=0.0055$ (Student's unpaired $t$ test). Data are mean \pm SEM. electron micrographs (Fig. 3b), we determined the g-ratio, which is defined by the inner to the outer diameter of the myelin sheath, of control and $\mathrm{KO}$ mice and found a similar distribution of the values on the scatter plot (Fig. 3c). Consequently, there was no significant difference in the average g-ratio in both groups (Fig. $3 d)$. We did, however, observe a redistribution of axon size. Interestingly, we found a significantly lower number of smalldiameter axons $(<1 \mu \mathrm{m})$ and an increase in large-diameter axons $(>1 \mu \mathrm{m})$ (Fig. $3 e$ ). On counting oligodendrocyte nuclei, we did not find any significant change in the KO optic nerve (Fig. $3 f$ ). We also did not observe any significant difference in the number of axons in the optic nerve (Fig. $3 g$ ). We did, however, find a significant increase in degenerated axons in the $\mathrm{KO}$ optic nerve (Fig. 3 h). Because of the humane endpoint, we could not examine whether or not the degeneration of axons would progress in older animals.

With further histological analyses of the white matter in the cerebellum and the corpus callosum, we found a significantly larger number of $\mathrm{Iba}^{+}$microglial and $\mathrm{GFAP}^{+}$astroglial cells in the former but not in the latter (Fig. $4 a-d$ ). The lumbar section of the spinal cord, however, displayed a strong increase in $\mathrm{Iba}^{+}$and $\mathrm{GFAP}^{+}$cells (Fig. 4e,f). Of note, neither microglia nor astrocytes accumulated in a focal manner in the spinal cord. In addition, we performed qPCR on cerebellar mRNA transcribed into cDNA to investigate the presence of anti-inflammatory and proinflammatory markers. Among the factors examined, we found an increase of both anti-inflammatory and proinflammatory indicators, but only the proinflammatory cytokine Ip-10/Cxcl10 (interferon gamma-induced protein 10) was significantly upregulated (Fig. $4 g, h)$.

To get an insight into the global changes of the myelin proteome in the CNS upon loss of Fbxo7, we isolated myelin from brain and subjected the material to quantitative mass spectrometry and determined the upregulated and downregulated proteins. Mitochondrial structural proteins and metabolismassociated proteins, in particular those that are responsible for mitochondrial functions, were the largest groups of the significantly downregulated proteins (Fig. 5a,b; Fig. 5-1, available at https://doi.org/10.1523/JNEUROSCI.3094-18.2019.f5-1). Among the top score upregulated proteins, we identified GST $\pi$ l (Fig. $5 c$; Fig. 5-1, available at https://doi.org/10.1523/JNEUROSCI.309418.2019.f5-1). GST $\pi 1$ is a detoxification enzyme for ROS that is exclusively expressed by oligodendrocytes (Tansey and Cammer, 1991). With immunostainings of the spinal cord, we confirmed the upregulation of GST $\pi 1$ in the CNS of KO mice compared with control animals (Fig. $5 d$ ). In contrast, we did not find any change in the level of major myelin proteins, such as PLP (Fig. $5 e$ ). In summary, we found that, while deletion of $\mathrm{Fbxo} 7$ in oligodendrocytes did not affect myelination or triggered the demise of these cells, it led to subliminal cell stress indicated by microgliosis and astrogliosis, the upregulation of proinflammatory markers, and detoxifying enzymes in oligodendrocytes.

Because the $\mathrm{KO}$ mouse was characterized by a progressive paresis of the hind limbs, we focused our analyses on the PNS. We first turned to electron microscopy to examine the integrity of the sciatic nerve of control and $\mathrm{KO}$ mice. Semithin sections already revealed a dramatic pathology with large areas void of healthy sciatic nerve components (Fig. $6 a$ ), whereas other regions were seemingly unaffected. With higher-magnification electron micrographs, we discovered obvious pathologies, which are described in the following analyses (Fig. 6b). We first determined whether the pathology included defects in myelination, but we did not find any change in the distribution of the g-ratio on the 
a

Down-regulated proteins in CNS myelin

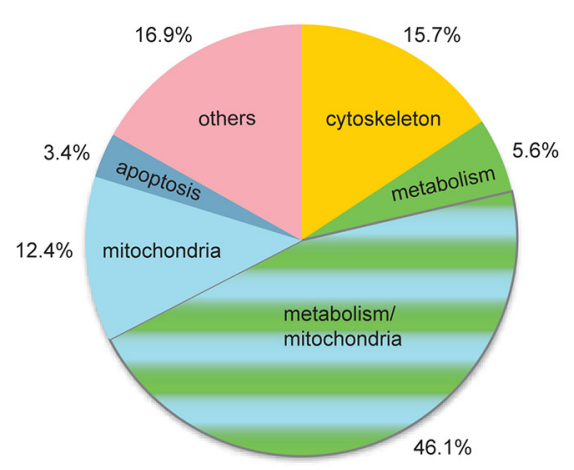

C

Up-regulated proteins in CNS myelin

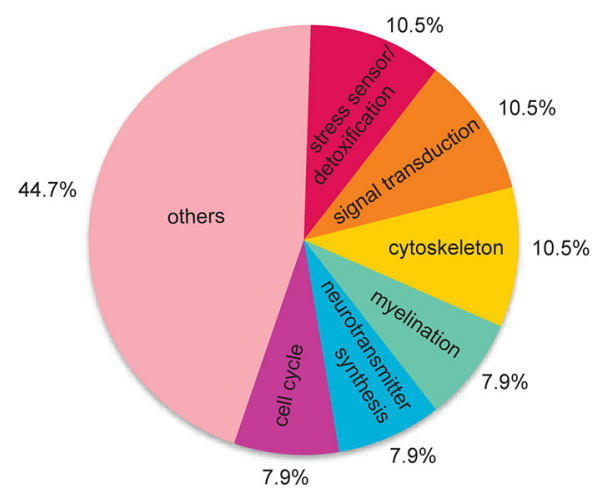

b

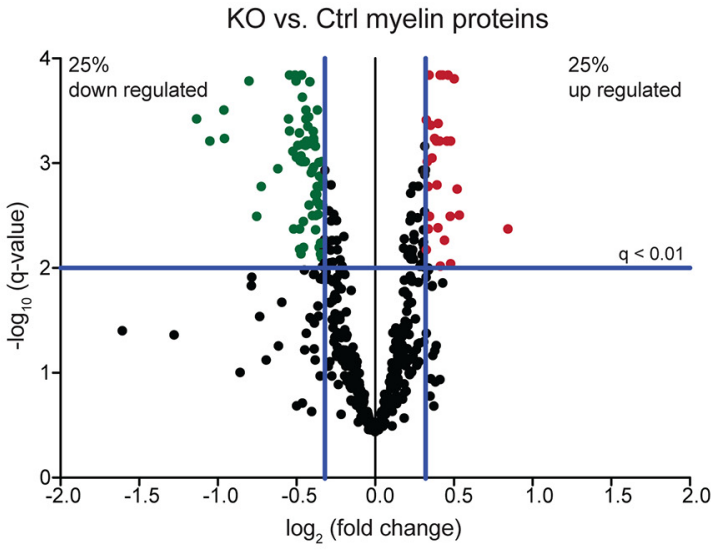

- significantly up regulated

- significantly down regulated

- non-significant

detected CNS myelin proteins: 522 total

up regulated proteins: 232 total

down regulated proteins: 290 total

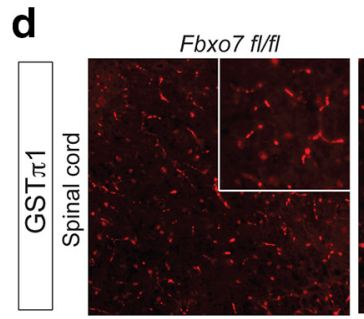

d

e

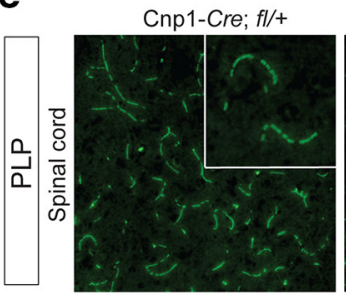

Cnp1-Cre

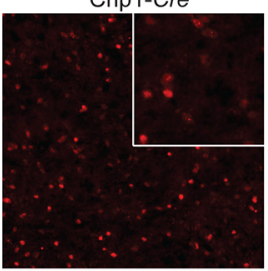

Cnp1-Cre; fl/fl

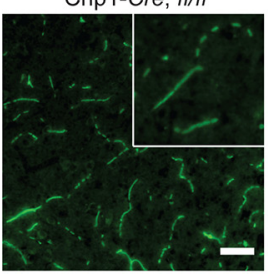

Cnp1-Cre; fl/fl
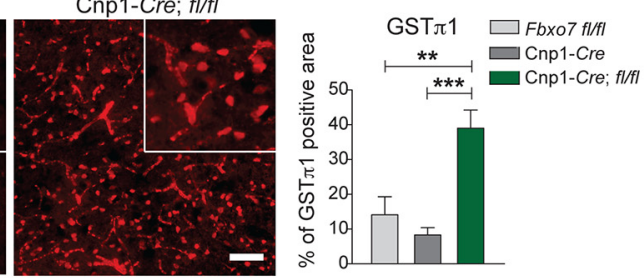

PLP

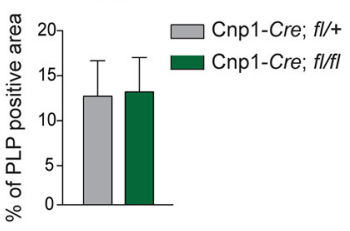

Figure 5. Histological and CNS mass spectrometry analyses of the Cnp1-Cre;fl/fl mice. $\boldsymbol{a}$, Purified myelin from brain of female control and Cnp1-Cre;fl/fl mice was analyzed using quantitative mass spectrometry. Downregulated functional protein groups displayed in pie chart were determined based on the number of proteins yielded in each term. Proteins displayed in pie charts adhere to the following criteria: $q<0.01$ and 25\% decrease in fold change. See Figure 5-1 (available at https://doi.org/10.1523/JNEUROSCI.3094-18.2019.f5-1) for complete dataset of CNS myelin proteome. $\boldsymbol{b}$, Purified myelin from 3-month-old, female control and (np1-Cre;fl/fl brains (CNS) was analyzed by quantitative mass spectrometry. The mean of five biological replicates per genotype and two technical replicates per animal was analyzed using the $\log 2 \mathrm{cKO} / \mathrm{control}$ ratio (= fold change). Cnp1-Cre; fl/fl values were normalized to control. Volcano plot displays downregulated and upregulated proteins from Cnp1-Cre;fl/fl compared with control. Blue vertical and horizontal lines indicate the filtering criteria $(q<0.01$, fold change $[\mathrm{FC}]-1.25$ and 1.25). $\mathrm{FC} \pm 1.25$ indicates peptide levels decreased or increased by $25 \%$, respectively. Red and green dots represent proteins that adhere to these criteria. c, Purified myelin from brain of female control and Cnp1-Cre; fl/fl mice was analyzed using quantitative mass spectrometry. Upregulated functional protein groups displayed in pie chart were determined based on the number of proteins yielded in each term. Proteins displayed in pie charts adhere to the following criteria: $q<0.01$ and $25 \%$ increase in fold change. See Figure 5-1 (available at https://doi.org/10.1523/JNEUROSCI.3094-18.2019.f5-1) for complete dataset of CNS myelin proteome. $\boldsymbol{d}$, Immunohistochemical staining of GST $\pi 1$ in spinal cord of male and female Cnp1-Cre,fl/fl mice and control groups; 3 animals per genotype were included in the analysis. ${ }^{* *} p<0.01$ (one-way ANOVA, Bonferroni test). ${ }^{* * *} p<0.001$ (one-way ANOVA, Bonferroni test). Data are mean \pm SEM. Scale bar, $50 \mu \mathrm{m}$. $\boldsymbol{e}$, Immunohistochemical staining of PLP in spinal cord of male and female Cnp1-Cre;fl/fl mice and control groups; 3 animals per genotype were included in the analysis. Data are mean \pm SEM. Scale bar, $50 \mu \mathrm{m}$. 

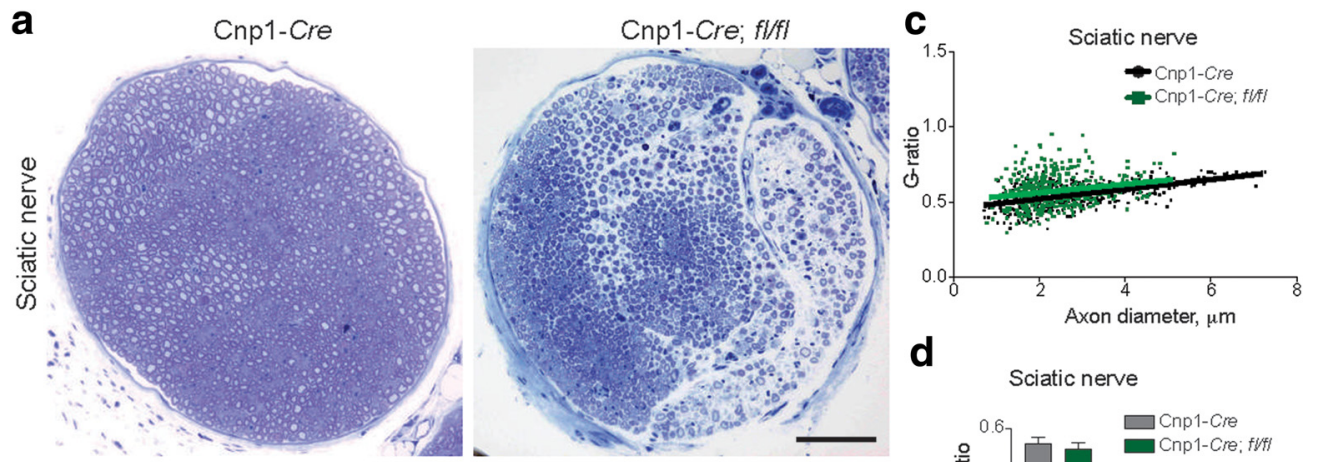

d

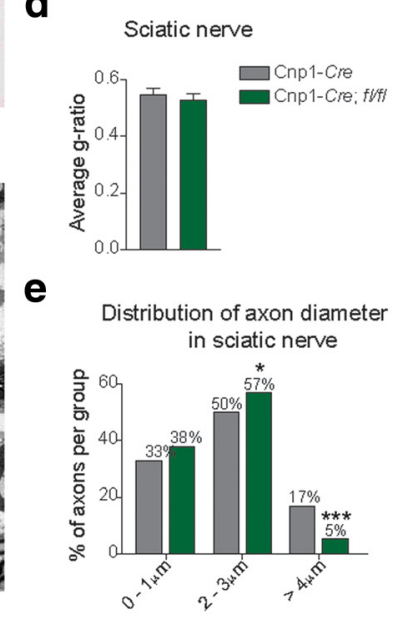

b

Cnp1-Cre

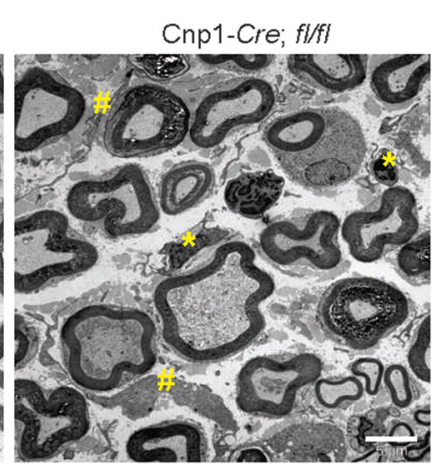

f

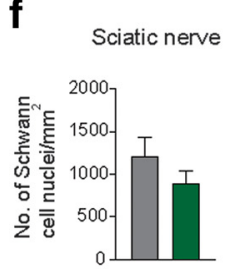

g
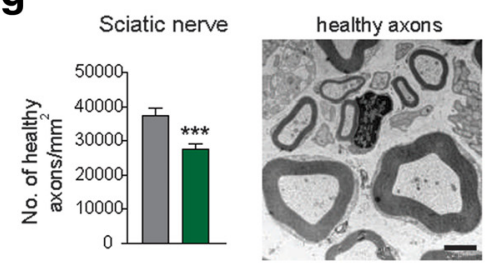

h
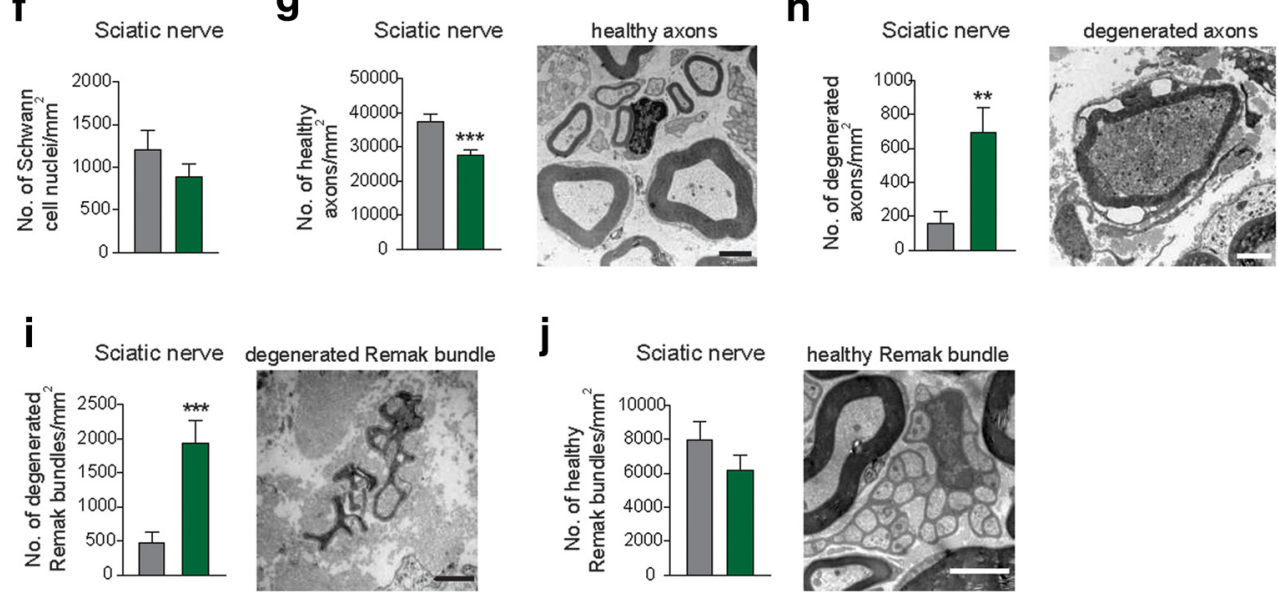

Figure 6. Loss of $F b \times 07$ triggers peripheral neuropathy without effects on myelination. $\boldsymbol{a}$, Semithin sections of the sciatic nerve of female control and Cnp1-Cre; $f$ / $f f l$ mice. Scale bar, $20 \mu \mathrm{m}$. $\boldsymbol{b}$, Electron micrographs of sciatic nerve isolated from female control and Cnp1-Cre,fl/fl mice. * Macrophages. "Fibroblasts. Scale bar, $5 \mu$ m. $\boldsymbol{c}, \boldsymbol{d}$, Sciatic nerve cross-sections of 3-month-old, female Cnp1-Cre and Cnp1-Cre,fl/fl mice were analyzed. Four mice per genotype and 100 axons per mouse were included in the g-ratio analyses displayed in a scatter plot (c) or as average values. $\boldsymbol{d}$, Data are mean \pm SEM. $e$, Distribution of axon caliber in sciatic nerve of control and (np1-Cre,fl/fl mice. The percentage of axons per group was analyzed. ${ }^{*} p<0.05$ ( $\chi^{2}$ test). ${ }^{* * *} p<0.001$ ( $\chi^{2}$ test). $\boldsymbol{f}$, Electron microscopy analysis of average number of Schwann cell nuclei per $/ \mathrm{mm}^{2}$. Data are mean $\pm \mathrm{SEM} . \boldsymbol{g}$, Electron microscopy analysis of average number of myelinated axons. ${ }^{* * *} p=0.0002$ (Student's unpaired $t$ test). Data are mean \pm SEM, together with representative electron micrograph. Scale bar, $2 \mu \mathrm{m} . \boldsymbol{h}$, Electron microscopy analysis of average number of degenerated axons and representative electron micrograph thereof. ${ }^{* *} p=0.001$ (Student's unpaired $t$ test). Data are mean \pm SEM. Scale bar, $2 \mu \mathrm{m} . \boldsymbol{i}, \boldsymbol{j}$, Electron microscopy analysis of average number of degenerated Remak bundles $/ \mathrm{mm}^{2} .{ }^{* * *} p=0.002$ (Student's unpaired $t$ test). $\boldsymbol{i}$, Data are mean \pm SEM and healthy Remak bundles $/ \mathrm{mm}^{2} . \boldsymbol{j}$, Data are mean \pm SEM. Scale bars: $\boldsymbol{i}, 1 \mu \mathrm{m} ; \boldsymbol{j}, 2 \mu \mathrm{m}$.

scatter plot (Fig. $6 c$ ) or any significant difference in the average g-ratio of control (Cnp1-Cre) and Cnp1-Cre;fl/fl mice (Fig. 6d), indicating that myelination per se was not affected. The scatter plot, however, revealed a smaller population of large-diameter axons in the KO mice compared with control animals. Analysis of the distribution showed a significant reduction of axons $>4 \mu \mathrm{m}$ (Fig. 6e).

While we discovered only a downward trend in the average number of Schwann cell nuclei in the KO sciatic nerve compared with control (Fig. $6 f$ ), we found a significant decrease in the number of myelinated axons (Fig. $6 \mathrm{~g}$ ), reflected in the loss of sciatic nerve components in the severely affected areas. The elec- tron micrographs also displayed a significant increase in degenerated axons of the sciatic nerve of Cnp1-Cre; fl/fl mice (Fig. 6h). In contrast to the healthy axons, we find accumulations of organelles, such as mitochondria, in the degenerated axons. The affected areas also displayed a significantly increased number of degenerated Remak bundles at various stages of demise (Fig. 6i). Consistently, the number of intact Remak bundles was slightly reduced (Fig. 6j). We did not observe any onion bulb formations that would indicate degeneration of Schwann cells.

In line with the increase in degenerated axons, we found a clear and significant increase in $\mathrm{APP}^{+}$accumulations in immunohistochemical analyses of the sciatic nerve (Fig. 7a), under- 
scoring the compromised axonal health. In contrast, our analyses revealed little or no difference in the major myelin protein MBP in the sciatic nerve (Fig. $7 b$ ). The axonal degeneration was also accompanied by an increase in Ibal reactivity, indicating the presence of peripheral immune cells (Fig. $7 c$ ). We then tested the idea that Schwann cells respond to the axonal degeneration by the upregulation of the cytoskeletal protein GFAP, typically expressed by nonmyelinating Schwann cell and by cells, which have lost axonal contact (Jessen et al., 1990; Jessen and Mirsky, 2016). While there was little to no GFAP reactivity in control mice, Cnp1-Cre; fl/fl sciatic nerves showed a significant upregulation of GFAP (Fig. $7 d$ ).

Consistent with the Ibal reactivity, electron micrographs of the sciatic nerve of Cnp1-Cre;fl/fl mice confirmed the significant invasion of macrophages (Fig. 7e), which entered through blood vessels (Fig. $7 f$ ). We found macrophages that endocytosed entire axon-myelin units (Fig. $7 g$ ) as well as foamy macrophages that were packed with endocytosed material (Fig. 7h). Furthermore, we detected fibrosis (Fig. 7i), a close contact between endocytosing macrophages and fibroblasts (Fig. 7j), and edema (Fig. 7k). Interestingly, we also found macrophages and fibroblasts mingling with healthy myelinated axons and Remak bundles in the seemingly unaffected areas of the sciatic nerve. Together, although loss of FBXO7 in Schwann cells had no effect on myelination, it resulted in a peripheral neuropathy characterized by the focal degeneration of axons and Remak bundles and fibrosis together with the invasion of macrophages.

With electrophysiological examinations of the sciatic nerve in the living $\mathrm{KO}$ mice, we measured a dramatic reduction in CMAP (Fig. $8 a$ ) and a moderate yet significant reduction of the NCV (Fig. $8 b$ ), but no difference in DML (Fig. $8 c$ ), suggesting an axonal defect without major damage to the myelin. These results are consistent with an axonal, but not demyelinating phenotype, and in line with the mild changes in NCV of CMT Types 2 versus Type 1 patients or in respective animal models (Sereda and Nave, 2006).

To determine the global protein changes in the $\mathrm{KO}$ sciatic nerve, we performed a quantitative mass spectrometry analysis of purified myelin isolated from control (Cnp1-Cre;fl/+) and Cnp1-Cre; fl/fl sciatic nerves. Among the significantly downregulated proteins, we found mostly a similar change in mitochondrial and metabolism-associated in addition to cytoskeletal proteins and protein modification enzymes (Fig. $8 d, e$ ), consistent with the loss of myelinated axons. The results of the upregulated proteins, such as immunoglobulins, showed a massive increase in immune response (Fig. 8f; Fig. 8-1, available at https://doi.org/ 10.1523/JNEUROSCI.3094-18.2019.f8-1), which supports the inflammation signs detected in the sciatic nerve upon loss of Fbxo7.

In our previous study, we learned that loss of FBXO7 affects proteasome activity in the brain and in heterologous HEK293T cells (Vingill et al., 2016), but we did not further dissect the activity of the proteasome in different cell types of the nervous system. To determine whether loss of FBXO7 in Schwann cells affects their proteasome activity, we first generated an FBXO7 RNAi cell line based on the murine Schwann cell line MSC80 (Boutry et al., 1992), and validated the efficient knockdown of FBXO7 (Fig. 9a). Using the control and FBXO7 knockdown cell line, we performed proteasome activity assays. Here, cell lysates are mixed with an artificial substrate conjugated to a fluorophore. The measured fluorescence reflects the chymotrypsin-like activity of the 20S core subunit PSMB5. We found a $40 \%$ reduction in the knockdown cell line compared with control cell lines (Fig. $9 b$ ). Having the $\mathrm{Fb}_{0} 0 \mathrm{7}^{-1-}$ mouse line available, we cultured pri- mary Schwann cells from $\mathrm{Fb}_{0} 07^{-/-}, \mathrm{Fbxo7}^{+/-}$and $\mathrm{Fb} \times \mathrm{O} 7^{+/+}$ mice. With immunoblotting, we subsequently confirmed the loss or reduction of FBXO7 in homozygous and heterozygous cells, respectively, (Fig. 9c). Additionally, we detected the expression of the Schwann cell marker SOX10 but no expression of nonSchwann cell cytoskeletal proteins (Fig. 9c). In $\mathrm{Fbxo}^{-/-}$ Schwann cells, we found a significantly reduced proteasome activity compared with $\mathrm{Fbxo7}^{+/-}$and $\mathrm{Fbxo7}^{+/+}$cells (Fig. 9d). Because the time window of the Schwann cell culture protocol allowed us to isolate cerebella from the same animals, we simultaneously cultured CGNs and subjected them to the proteasome activity assay. Interestingly, we found that loss of $\mathrm{Fbxo} 7$ had little or no effect on their proteasome activity (Fig. 9e), suggesting that, in contrast to CGNs, Schwann cells are sensitive to FBXO7 loss.

Having identified FBXO7 as a critical factor for axon-glia interaction in the PNS, we examined the loss of $\mathrm{Fbxo7}$ on the axonglia interaction after development in the adult animal. Here, we used an inducible system to breed $\mathrm{Fbxo} 7 \mathrm{fl} / \mathrm{fl}$ mice with the Plp1CreERT2 driver line. We injected these mice and the control group with tamoxifen at 2 months of age when myelination was completed and assessed the motor skills at 5, 7, and 9 months of age (Fig. 10a), followed by histological analyses. Genotyping was performed to identify the KO and control group (Fig. 10b). In addition, we performed immunoblotting analysis to establish a reduction in FBXO7 levels. Here, cortical tissue with little or no white matter contamination or cerebellar tissue that harbors large white matter areas were lysed and examined using the FBXO7 antibody. FBXO7 reactivity was reduced in cerebellar lysates but not in cortical lysates of PLP-CreERT2; fl/fl mice (Fig. $10 c$ ), indicating the successful tamoxifen-triggered recombination. We also determined the weight of control and Plp1-CreERT2; fl/fl mice and found that, starting at 5 months of age, the KO mice were significantly lighter compared with 3-month-old mice (Fig. 10d). We first tested the control and KO group for hindlimb clasping, which showed a slight decrease of the score at the latest time point of analysis (Fig. 10e). The KO mice showed no difference in their performance on the balance beam, in the open field arena or in the wire hang test (Fig. 10f-j), suggesting that the mice are fully ambulant and with proper forelimb/hindlimb coordination. In addition, the KO mice showed no deficit in the pole test or on the inverted grid (Fig. 11a,b), nor did they show any signs of anxiety in the elevated plus maze or sensory deficits on the hot plate (Fig. 11c,d). Plp1-CreERT2;fl/fl mice did, however, perform significantly worse on the rotarod compared with control mice at every time point tested (Fig. 11e), suggesting a persisting impairment that affects the motor endurance.

To determine whether the sciatic nerve revealed a similar pathology compared with the Cnpl-Cre; fl/fl mice, we examined electron micrographs. The overall integrity of the sciatic nerve was not compromised (Fig. 12a). The analysis of the g-ratio revealed no difference between $\mathrm{KO}$ and control mice (Fig. 12b,c) and no redistribution of axonal diameters as observed in the Cnp1-Cre;fl/fl mice (Fig. 12d). We also did not observe an increase in fibrosis (Fig. 12e) or degenerated Remak bundles (Fig. 12f). We did, however, observe a slight increase in infiltrating macrophages into the sciatic nerve in the Plp1-CreERT2; fl/fl mice (Fig. 12g) and a significant increase in degenerated axons (Fig. 12h), although to a less severe degree compared with Cnp1-Cre;fl/fl mice. These data indicate that the disruption of Fbxo7 expression in Schwann cells of the mature PNS leads to a mild, late-onset neuropathy. 


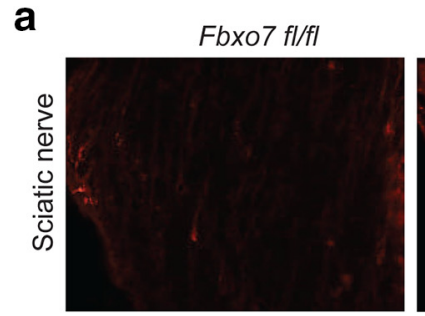

b

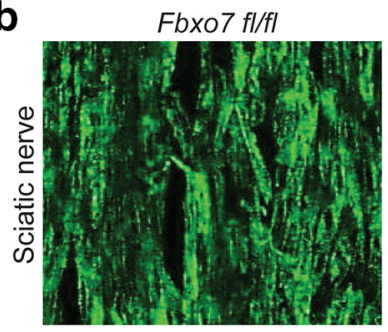

C

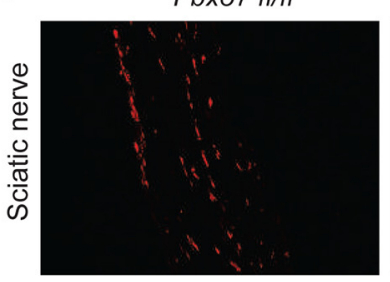

d

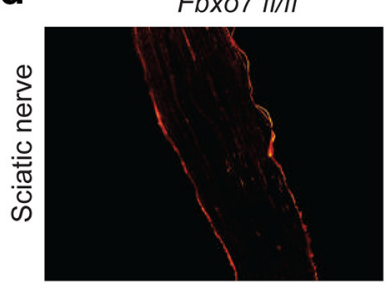

e $f$

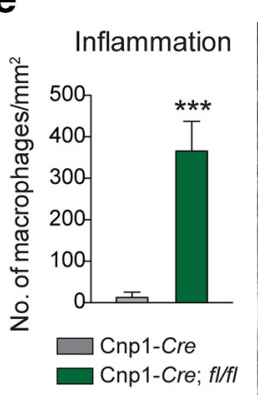

i

Fibrosis

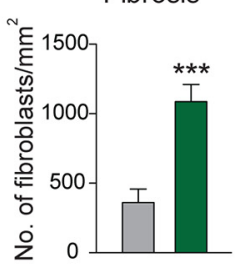

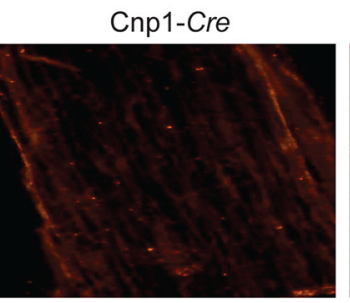

Cnp1-Cre; fl/fl

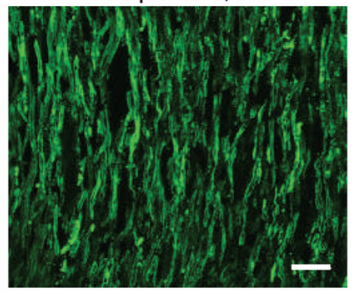

Cnp1-Cre
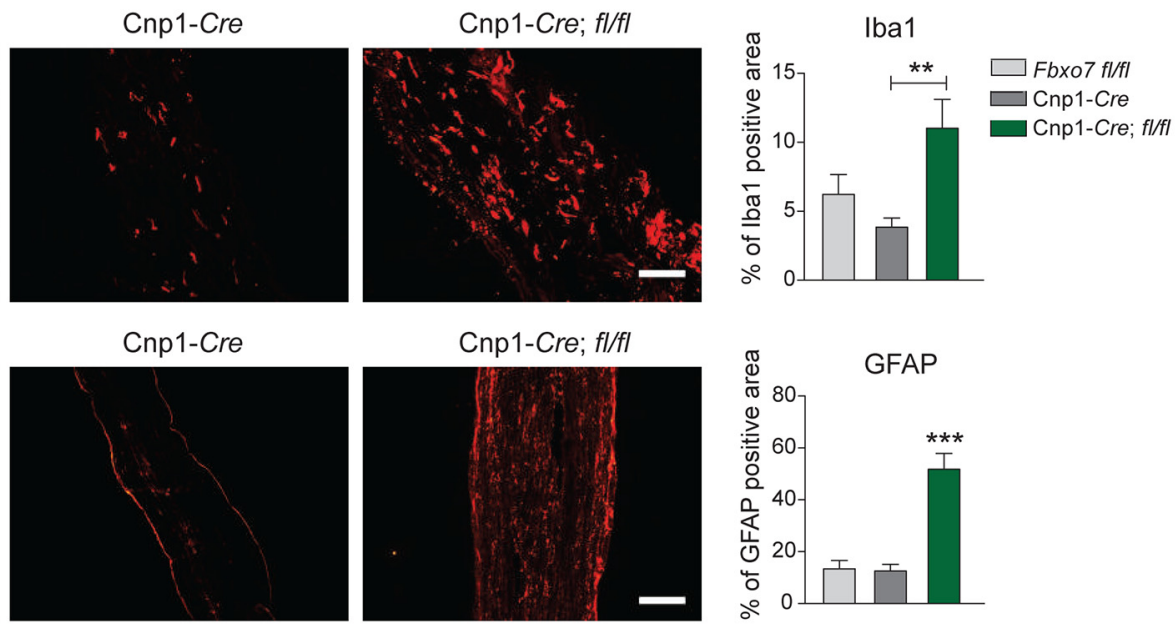

h
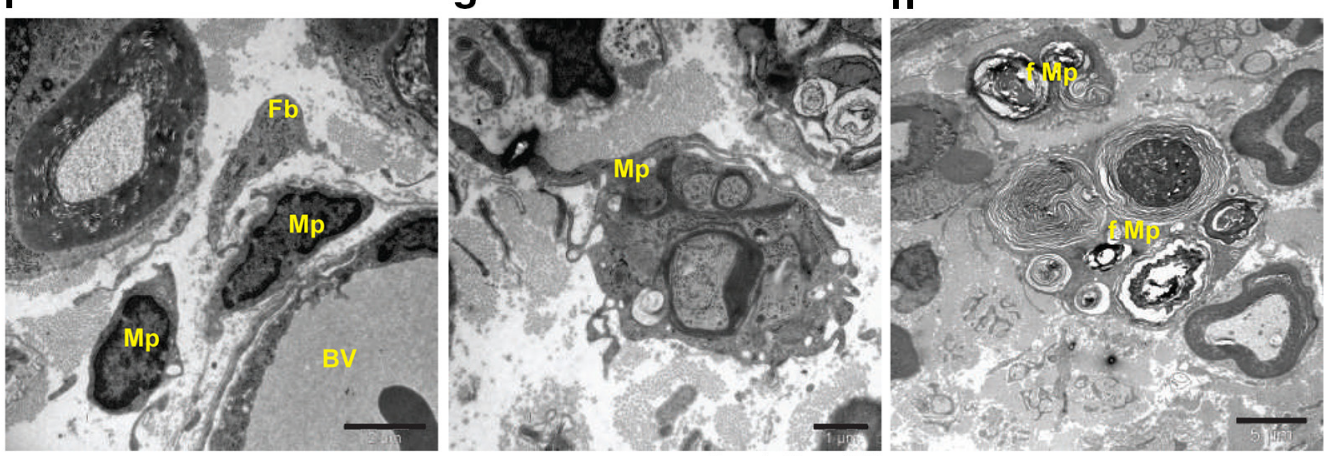

Cnp1-Cre; fl/ff
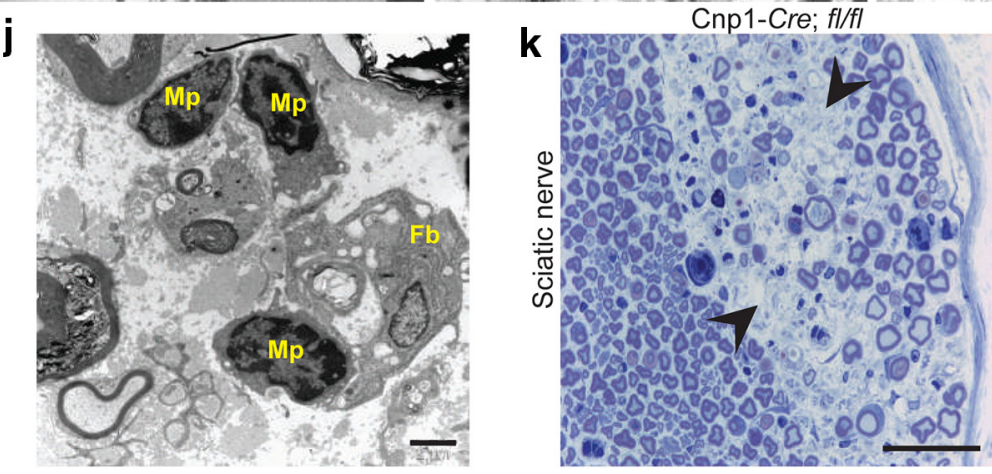

Figure 7. Pathological changes in the sciatic nerve. $\boldsymbol{a}, \boldsymbol{b}$, Longitudinal sections of sciatic nerves isolated from male control and (np1-Cre;fl/fl mice were subjected to immunohistochemistry with the APP antibody. ${ }^{*} p<0.05$ (one-way ANOVA, Bonferroni test). $\boldsymbol{a}$, Data are mean \pm SEM or MBP antibody. $\boldsymbol{b}$, Data are mean \pm SEM. Scale bar, $50 \mu \mathrm{m}$. $\boldsymbol{c}, \boldsymbol{d}$, Longitudinal sections of sciatic nerves isolated from male control and Cnp1-Cre;fl/fl mice were subjected to immunohistochemistry with the lba1. ${ }^{* *} p<0.01$ (one-way ANOVA, Bonferroni test). c, Data are mean \pm SEM or GFAP antibody. ${ }^{* * *} p<0.001$ (one-way ANOVA, Bonferroni test). $\boldsymbol{d}$, Data are mean \pm SEM. Scale bar, $100 \mu \mathrm{m}$. $\boldsymbol{e}-\boldsymbol{h}$, Macrophages were counted in female WT and K0 mice. (Figure legend continues.) 
a

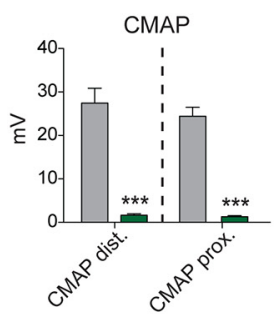

d

\section{Down-regulated proteins in PNS myelin}

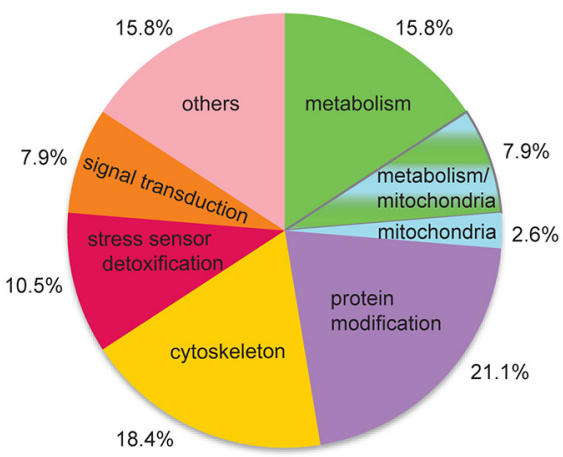

f

Up-regulated proteins in PNS myelin

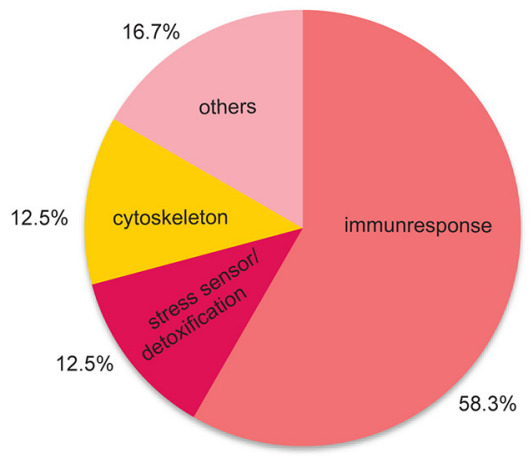

C

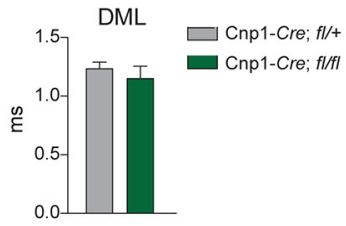

e

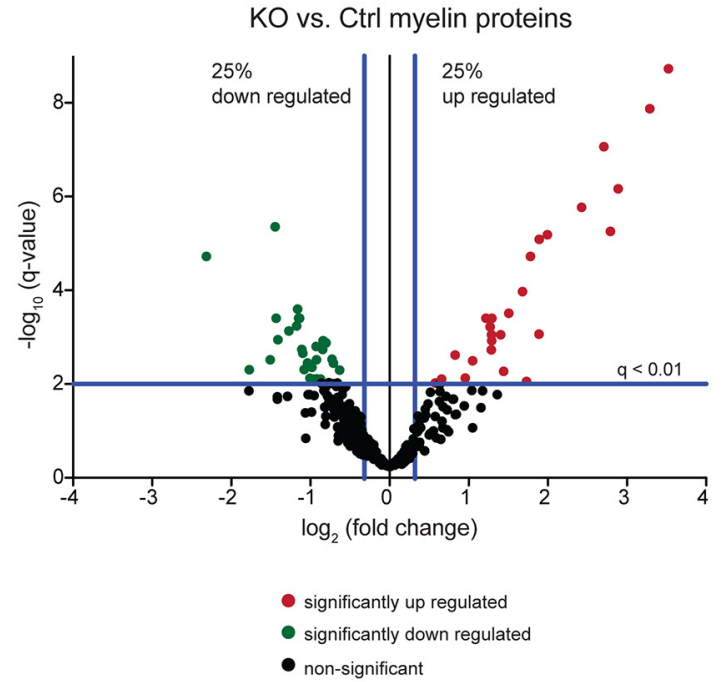

detected PNS myelin proteins: 368 total

up regulated proteins: 131 total

down regulated proteins: 237 total

Figure 8. Electrophysiological and mass spectrometry analyses of the Cnp1-Cre,fl/fl mice. $\boldsymbol{a}$-c, Electrophysiological recordings of sciatic nerves of 2-month-old, male and female control and Cnp1-Cre,fl/fl mice assessing CMAP. ${ }^{* * *} p<0.0001$ (Student's unpaired $t$ test). Data are mean \pm SEM. $\boldsymbol{a}$, NCV. ${ }^{* *} p=0.0017$ (Student's unpaired $t$ test). Data are mean \pm SEM. $\boldsymbol{b}$, DML. Data are mean \pm SEM. $\boldsymbol{c}$, Six mice per condition were included in the analyses. $\boldsymbol{d}$, Purified myelin from sciatic nerve of male and female control and (np1-Cre;flffl mice was analyzed using quantitative mass spectrometry. Downregulated functional protein groups displayed in the pie chart were determined based on the number of proteins yielded in each term. Proteins displayed in pie charts adhere to the following criteria: $q<0.01$ and 25\% decrease in fold change. See Figure 8-1 (available at https://doi.org/10.1523/JNEUROSCI.3094-18.2019.f8-1) for complete dataset of PNS myelin proteome. e, Purified myelin from 3-month-old, male and female control and Cnp1-Crefflffl sciatic nerves (PNS) was analyzed by quantitative mass spectrometry. Nine pairs of sciatic nerves were pooled into 3 groups per genotype, each measured in duplicates and analyzed using the log2 $\mathrm{cKO} /$ control ratio. Values of (np1-Cre:fl/fl myelin were normalized to control. Volcano plot displays downregulated and upregulated proteins of $\mathrm{Cnp1-Cre;f/fl}$ myelin compared with control. Blue vertical and horizontal lines indicate the filtering criteria $(q<0.01$, fold change [FC] -1.25 and 1.25$)$. FC \pm 1.25 indicates peptide levels decreased or increased by $25 \%$, respectively. Red and green dots represent proteins that adhere to these criteria. $\boldsymbol{f}$, Purified myelin from sciatic nerve of male and female control and Cnp1-Cre;fl/fl mice was analyzed using quantitative mass spectrometry. Upregulated functional protein groups displayed in pie chart were determined based on the number of proteins yielded in each term. Proteins displayed in the pie charts adhere to the following criteria: $q<0.01$ and 25\% increase in fold change. See Figure 8-1 (available at https://doi.org/10.1523/ JNEUROSCI.3094-18.2019.f8-1) for complete dataset of PNS myelin proteome.

(Figure legend continued.) $\quad{ }^{* * *} p<0.0001$ (Student's unpaired $t$ test). Data are mean \pm SEM. Among those were macrophages invading via the blood vessels ( $\boldsymbol{f}$, Scale bar, $2 \mu \mathrm{m})$, macrophages that have completed the engulfment of myelin-axon segments ( $\boldsymbol{g}$, Scale bar, 1 $\mu \mathrm{m})$, and foamy macrophages ( $\boldsymbol{h}$, Scale bar, $5 \mu \mathrm{m}$ ). Mp, Macrophage; $\mathrm{Fb}$, fibroblast; BV, blood vessel; f Mp, foamy macrophage. $\boldsymbol{i}, \boldsymbol{j}$, Fibroblasts were counted in female WT and KO mice. ${ }^{* * *} p<0.0001$ (Student's unpaired $t$ test). Data are mean \pm SEM. Representative electron micrograph of fibroblast in close contact with macrophages in the sciatic nerve of (np1-Cre;fl/fl mice (j). Mp, Macrophage; Fb, fibroblast. Scale bar, $2 \mu \mathrm{m}$. $\boldsymbol{k}$, Semithin section of the sciatic nerve of female Cnp1-Cre,fl/fl mice displaying edema (arrowheads). Scale bar, $20 \mu \mathrm{m}$.

\section{Discussion}

Myelinating cells are fundamental for the fast saltatory conduction and for the trophic support of axons (Saab et al., 2013; Saab and Nave, 2017). In this study, we described a critical role for the F-box protein FBXO7 in the axon-myelin unit. FBXO7 is widely expressed in the nervous system, including myelinating cells. While deletion of $\mathrm{Fbxo} 7$ in the oligodendrocytes or Schwann cells does not affect myelin biogenesis, we observe signs of degenera- 
a

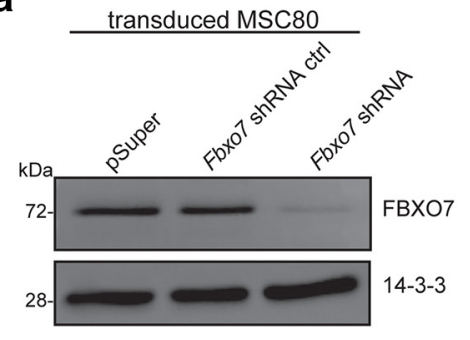

C

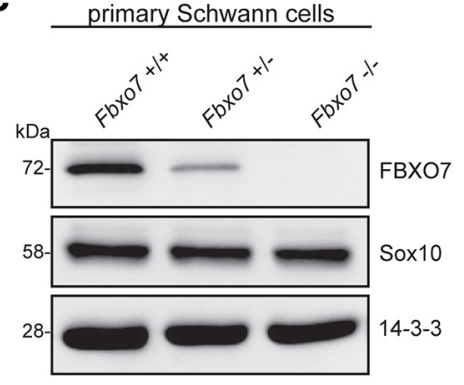

primary Schwann cells Cerebellum

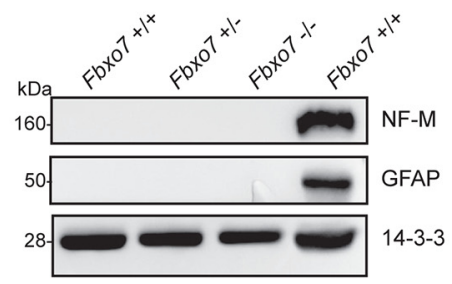

b

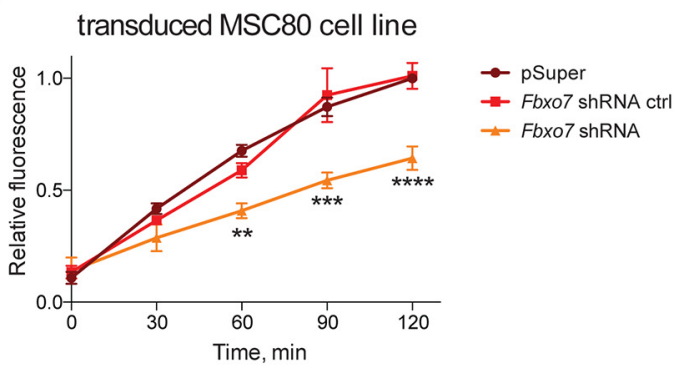

d primary Schwann cells

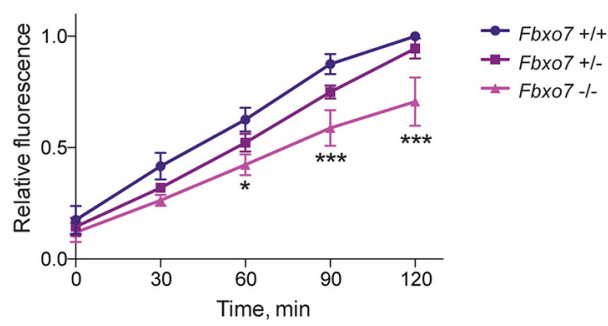

e cerebellar granule neurons

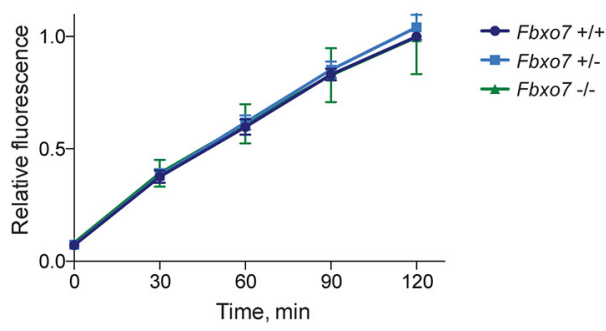

Figure 9. Fbxo7 knockdown or deletion leads to reduced proteasome activity in Schwann cells. $\boldsymbol{a}$, Lysates of MSC80 Schwann cells transduced with control vector (pSuper), FBX07 RNAi control (nonfunctional), or FBX07 RNAi were subjected to immunoblotting with the FBX07 and 14-3-3 antibodies. The latter served as loading control. $\boldsymbol{b}$, Lysates of MSC80 Schwann cells (control vector, control FBX07 RNAi control [nonfunctional], or FBX07 RNAi) were subjected to proteasome activity assay. Four independent experiments were included in the analyses. ${ }^{* *} p<0.01$ (two-way ANOVA, Bonferroni test). ${ }^{* * *} p<0.001$ (two-way ANOVA, Bonferroni test). ${ }^{* * *} p<0.0001$ (two-way ANOVA, Bonferroni test). Data are mean \pm SEM. c, Lysates of cultured primary Schwann cells from male and female WT, $\mathrm{FbxO}^{+/-}$, and $\mathrm{FbxO} 7^{-/-}$mice and $\mathrm{FbxO}^{+/+}$cerebellar lysates were subjected to immunoblotting with the FBX07, SOX10, NFM, GFAP, and 14-3-3 antibodies. The latter served as loading control. $\boldsymbol{d}$, Lysates of cultured primary Schwann cells from postnatal day 5 male and female $F b \times 07^{+/+}$, $F b \times 07^{+/-}$, and $F b \times 07^{-/-}$mice were subjected to proteasome activity assay. Four independent experiments were included in the analyses. ${ }^{*} p<0.05$ (two-way ANOVA, Bonferroni test). ${ }^{* * *} p<0.001$ (two-way ANOVA, Bonferroni test). Data are mean \pm SEM. $\boldsymbol{e}$, Lysates of cultured primary $\mathrm{CGNs}$ from male and female $\mathrm{Fbxo} 7^{+/+}, \mathrm{Fbxo}^{+/-}$, and $\mathrm{FbxO}^{-/-}$mice were subjected to proteasome activity assay. Five independent experiments were included in the analyses. Data are mean \pm SEM.

tion and inflammation in the CNS and an even more dramatic phenotype in the PNS. Here, loss of Fbxo7 triggers peripheral neuropathy characterized by axonal degeneration and macrophage invasion. This phenotype is particularly severe if $\mathrm{Fbxo7}$ is ablated early on and thus in contrast to a mild version of neuropathy caused by the postmyelination deficiency of Fbxo7.

FBXO7 is a subunit of the SCF E3 ubiquitin ligase, encoded by PARK15 and has been implicated in an atypical form of Parkinson's disease. This movement disorder was termed Parkinsonianpyramidal syndrome and is characterized by juvenile onset and a spectrum of symptoms and signs, which include, among others, bradykinesia, rigidity, Babinski sign, and cognitive deficits (Shojaee et al., 2008; Di Fonzo et al., 2009; Gündüz et al., 2014; YalcinCakmakli et al., 2014; Lohmann et al., 2015). A peripheral neuropathy accompanying this particular syndrome has not been reported yet, but other reports have suggested that axonal neuropathy correlates with idiopathic Parkinson disease to a much higher extent compared with control individuals (Manca et al., 2009; Toth et al., 2010; Rajabally and Martey, 2011). Further genetic studies investigated the prevalence of asymptomatic peripheral neuropathy in patients suffering from juvenile parkinsonism. Here, peripheral neuropathy characterized by denervation, abnormalities in motor conduction of peroneal nerve, in sural sensory conduction and sympathetic skin response, was diagnosed in $>50 \%$ of the Parkinson's disease patients with juvenile onset (Taly and Muthane, 1992). Individuals with Parkin mutations also showed an asymptomatic sensory axonal neuropathy (Ohsawa et al., 2005), supporting the view of peripheral neuropathy as a coexisting disorder of Parkinson's disease. Hence, it might be interesting to examine PARK15 patients for clinical features of peripheral neuropathy.

The milder pathology in the CNS stands in contrast to the strong pathology in the PNS. Increased axonal degeneration in the optic nerve together with the inflammation and astrogliosis in the brain and spinal cord upon $F B X O 7$ deletion may, however, reflect the initial phase of a progressive degeneration of CNS axons. Because of the humane endpoint dictated by the peripheral neuropathy, we can only speculate about the pathological course in older mice. Whether or not the axon-myelin unit in the CNS will ever be as severely affected as in the PNS requires a more 
a<smiles>CCOC(=O)OCC1CCCCCC1C</smiles>

PIp1-CreERT2; Fbxo7 fl/fl- mouse line

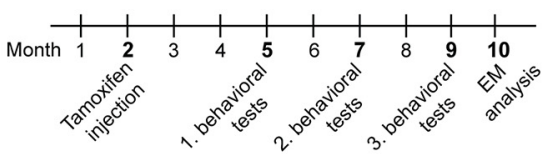

C

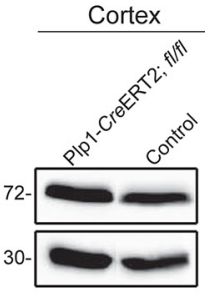

e

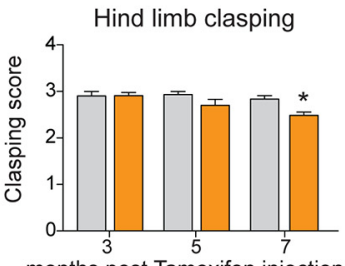

Cerebellum

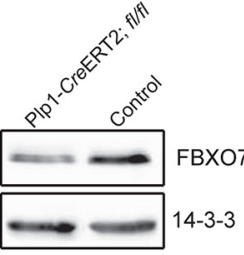

b

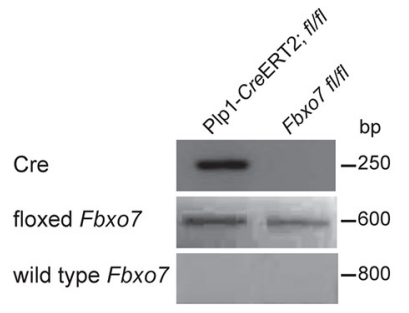

d

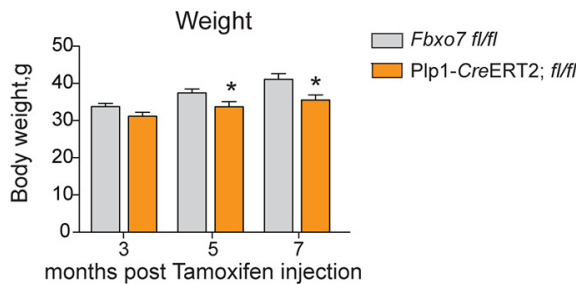

$6 \mathrm{~mm}$ Balance beam
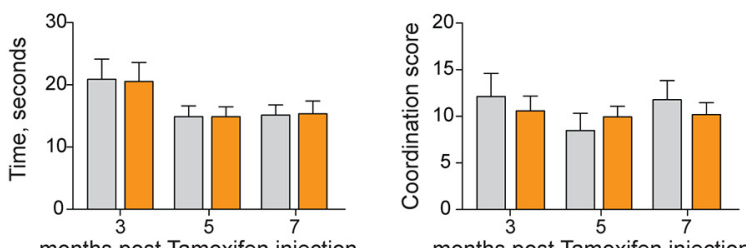

g

12mm Balance beam
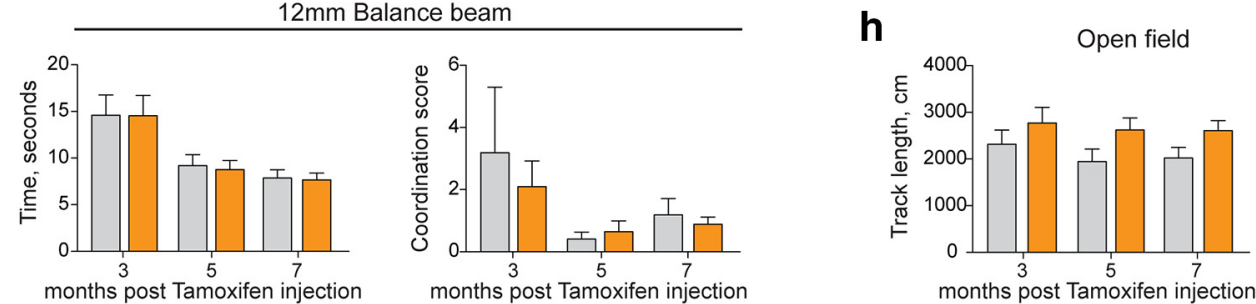

i

Open field

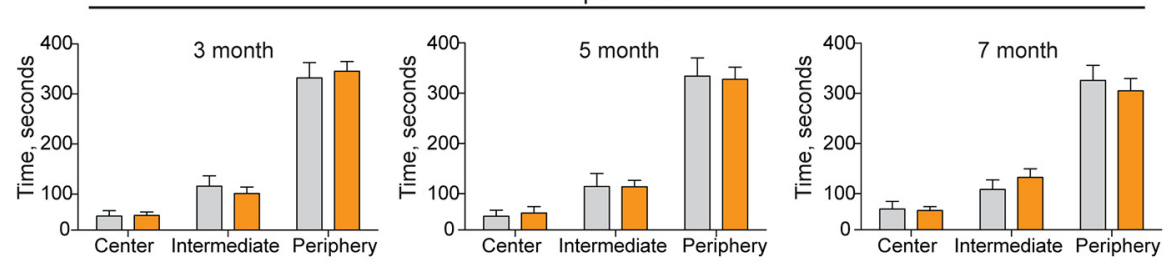

j

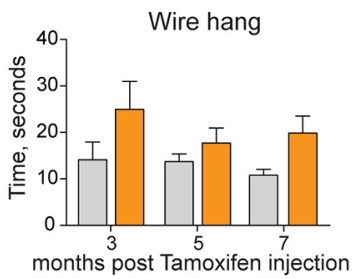

Figure 10. Behavioral analyses of PIp1-CreERT2;fl/fl and control cohorts I. $\boldsymbol{a}$, Schematic of experimental design. PIp1-CreERT2;fl/fl and control cohorts were injected with tamoxifen at 2 months of age. Analyses were performed at 5, 7, and 9 months of age. $\boldsymbol{b}$, Genotyping PCR of control Fbxo $7 f /$ fl and PIp1-CreERT2;fl/fl mice. c, Cortical and cerebellar lysates from male and female control and PIp1-CreERT2;fl/fl mice were immunoblotted with the FBX07 and 14 -3-3 antibodies. The latter served as loading control. $\boldsymbol{d}, \boldsymbol{e}$, The weight (d) and hindlimb clasping score (e) of 10 male $\mathrm{Fbxo} f f / f l$ and 11 male PIp1-CreERT2;fl/fl mice were determined. ${ }^{*} p<0.05$ (two-way ANOVA, Bonferroni test). Data are mean \pm SEM. $\boldsymbol{f}$-j, Ten male Fbxo7fl/fl and 11 male PIp1-CreERT2;fl/fl mice were subjected to balance beam test $(\boldsymbol{f}, \boldsymbol{g})$, open field test $(\boldsymbol{h}, \boldsymbol{i})$, or wire hang test $(\boldsymbol{j})$. Data are mean \pm SEM. 
a

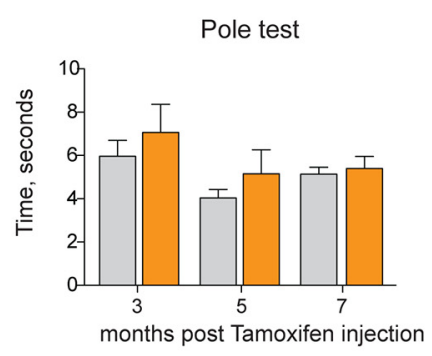

b

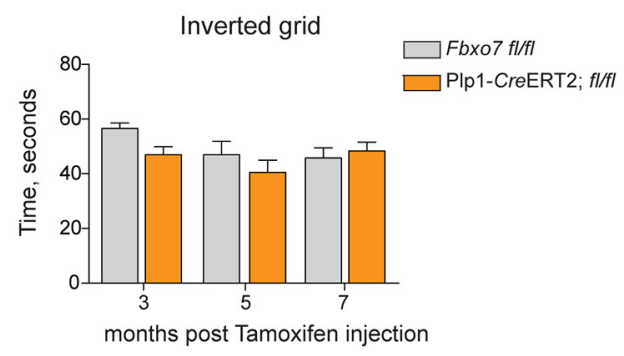

C

Elevated plus maze
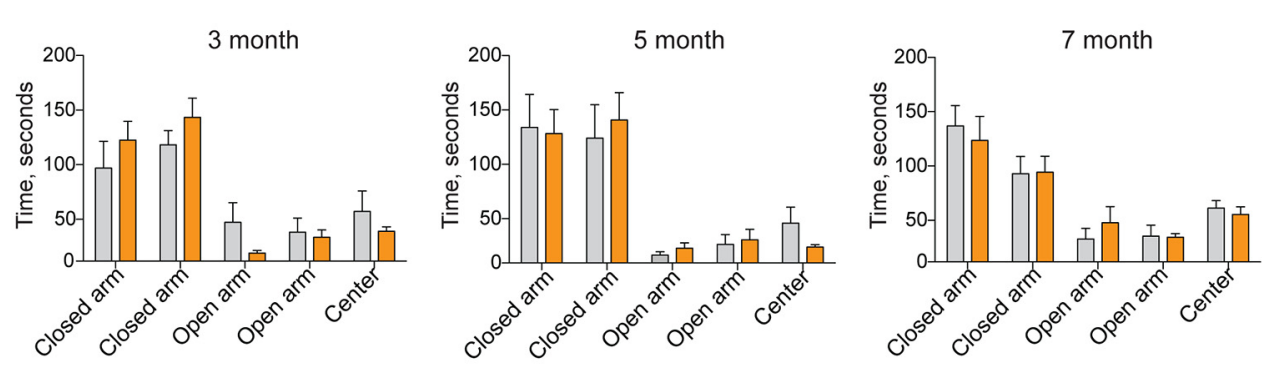

d

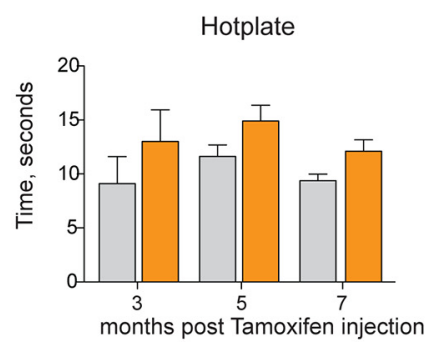

e

Rotarod

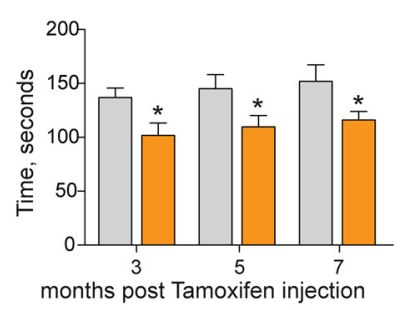

Figure 11. Behavioral analyses of Plp1-CreERT2;fl/fl mice control cohorts II. $\boldsymbol{a}-\boldsymbol{e}$, Ten male Fbxofl/fl and 11 male PIp1-CreERT2;fl/fl mice were subjected to pole test (a), inverted grid test (b), elevated plus maze test $(\boldsymbol{c})$, hotplate test $(\boldsymbol{d})$, and rotarod test $(\boldsymbol{e}) .{ }^{*} p<0.05$ (two-way ANOVA and Bonferroni test). Data are mean \pm SEM.

specific genetic approach. What is obvious, though, is that the loss of Fbxo7 during development contributes strongly to peripheral neuropathy, given that the conditional deletion of $\mathrm{Fbxo} 7$ in adult mice triggers a milder phenotype. Deletion of $\mathrm{Fbxo} 7$ in Schwann cells causes a full-blown neuropathy with degenerated axons but no apparent effect on myelin biogenesis. However, what can be observed is that myelin together with degenerating axons is cophagocytosed by macrophages, which contributes to the secondary loss of myelin. Furthermore, our findings led to the conclusion that the loss of contact with axons likely results in Schwann cells adopting a nonmyelinating state, indicated by the upregulation of GFAP in the sciatic nerve. GFAP is typically expressed by nonmyelinating Schwann cells and upregulated in Schwann cells that are deprived of axonal contact (Jessen et al., 1990). In conclusion, this sign of Schwann cell dedifferentiation is in line with observations in CMT mouse models characterized by damaged nerve fibers (Fledrich et al., 2014; Klein et al., 2014; Groh et al., 2015).

The neuropathology of the PNS displays a quite striking phenotype. We find a focal destruction of the sciatic nerve that is characterized by degenerated axons and Remak bundles, which are in turn characterized by empty collagen pockets or reduced to Remak cells only (Weis et al., 2012). We further observe an increase in fibroblasts, which are in close proximity with infiltrating macrophages, a scenario that has been previously found in CMT models (Groh et al., 2012). The macrophages are clearly respon- sible for the removal of the degenerating axons together with the myelin, which subsequently leaves edema in the inflammation foci. Other parts of the sciatic nerve appear completely normal with healthy myelinated axons and Remak bundles, but the impending infiltration of macrophages can already be observed. As we do not observe lymphocytes at the time of analysis, the macrophage invasion should foremost be viewed as a cleanup action following Wallerian degeneration of the axons. Focal inflammatory mechanisms that include colony stimulating factor-1induced increase in macrophage number may also amplify the devastating clearance of myelinated fibers (Groh et al., 2012, 2015).

The focal breakdown of the myelin-axon units in the sciatic nerve is a remarkable feature that may induce the focal activation of the innate immune response. Focal inflammation is however rather atypical for genetic neuropathies. For example, while CMT disease Type 2 (CMT2), harboring certain MPZ mutations, is characterized by a prominent axonal degeneration, mild or no demyelination, and only moderate reduction of nerve conduction velocity (Chapon et al., 1999; Shy et al., 2004; Finsterer et al., 2006), peripheral nerve biopsies of these CMT2 patients show a rather uniform pathology (Chapon et al., 1999; Senderek et al., 2000). Consistent with CMT2, we also find the depletion of large myelinated fibers.

FBXO7 plays also an important role in neurons for regulating motor functions (Vingill et al., 2016). In contrast to myelinating 
a
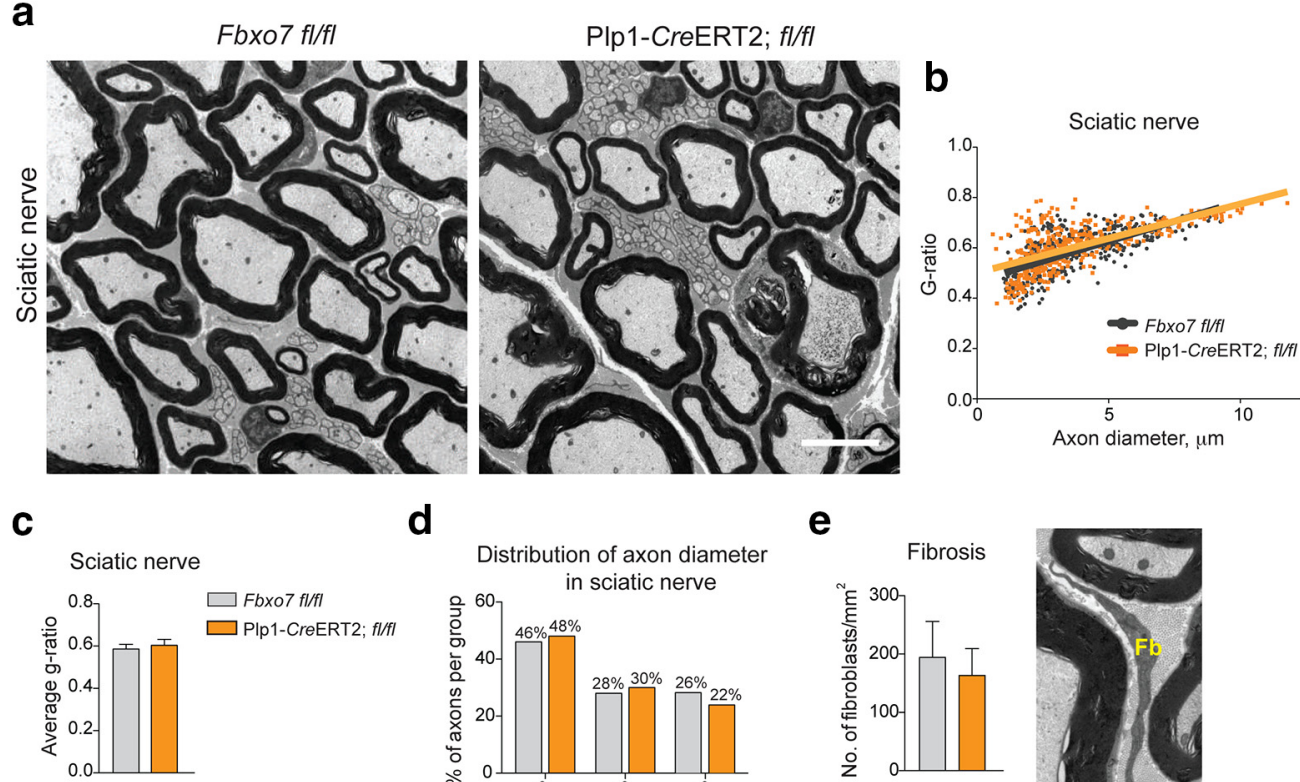

d

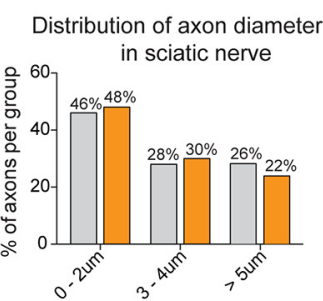

e

$\mathbf{f}$

\section{g}
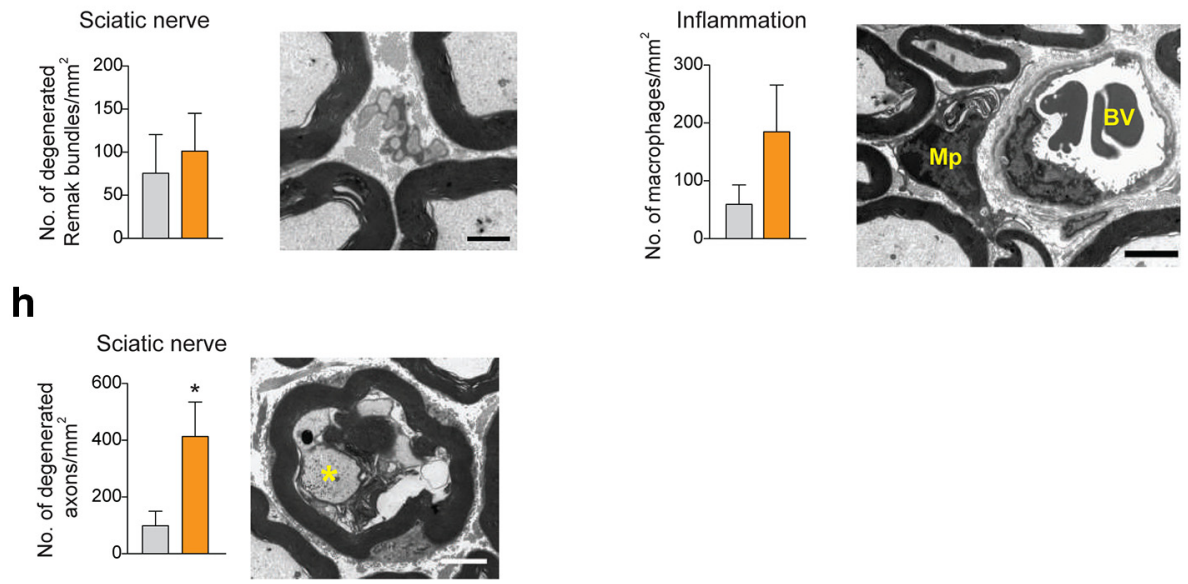

Figure 12. Electron microscopy analysis of sciatic nerves of Plp1-CreERT2;fl/fl and control mice. $a$, Representative electron micrographs of sciatic nerves isolated from 10-month-old Fbxo7fl/fl and PIp1-CrERT2;fl/fl mice. Scale bar, $5 \mu \mathrm{m} . \boldsymbol{b}, \boldsymbol{c}$, Sciatic nerve cross-sections of 10-month-old, male Fbxo7fl/fl and Plp1-CrERT2;fl/fl mice were analyzed. Four mice per genotype and 100 axons per mouse were included in the g-ratio analyses displayed in a scatter plot $(\boldsymbol{b})$ or as average values (c). Data are mean \pm SEM. $\boldsymbol{d}$, Distribution of axon caliber in sciatic nerve of control and PIp1-CrERT2; fl/fI mice. The percentage of axons per group was analyzed $(N-1)$. $\boldsymbol{e}$, Electron microscopy analysis of average number of fibroblasts $/ \mathrm{mm}^{2}$. Data are mean \pm SEM. Fb, Fibroblast. Scale bar, $2 \mu \mathrm{m}$. $\boldsymbol{f}$, Electron microscopy analysis of average number of degenerated Remak bundles $/ \mathrm{mm}^{2}$. Data are mean $\pm \mathrm{SEM}$. Scale bar, $2 \mu \mathrm{m}$. $\boldsymbol{g}$, Electron microscopy analysis of average number of macrophages $/ \mathrm{mm}^{2}$. Data are mean \pm SEM. Representative electron micrographs of invading macrophages (Mp), infiltrating sciatic nerve from blood vessels (BV). Scale bar, $2 \mu \mathrm{m}$. $\boldsymbol{h}$, Electron microscopy analysis of average number of degenerated axons $/ \mathrm{mm}^{2} .{ }^{*} p=0.0449$ (Student's unpaired $t$ test). Data are mean \pm SEM. Representative electron micrograph of degenerated shrunken axon (asterisk) and accumulation of pleomorphic, probably autophagic material in the adaxonal Schwann cell cytoplasm in Plp1-CrERT2;fl/fl mice. Scale bar, $2 \mu \mathrm{m}$.

cells, loss of Fbxo7 in neurons does not lead to any obvious signs of axonal degeneration (Vingill et al., 2016). These findings suggest that, while absence of $\mathrm{Fbxo7}$ in neurons has no effect on axonal health, its loss in myelinating cells is detrimental to axonal integrity. This raises the question of which mechanism in myelinating cells is dispensable for myelination but indispensable for the support of the axon-myelin unit. As of now, this is quite challenging to answer as E3 ubiquitin ligases, such as FBXO7SCF, are versatile enzymes implicated in multiple pathways. Our current understanding of FBXO7 is its regulatory role in proteasome assembly and activity (Vingill et al., 2016). As a consequence, systemic deletion of Fbxo7 in the brain results in a decrease in proteasome activity. Interestingly, we found that loss of Fbxo7 affects different cell types to a variable extent. Schwann cells appear to be very sensitive to proteasome inhibition. In line with this finding, the use of bortezomib, a reversible inhibitor of the catalytic proteasomal subunit PSMB5, has been applied to experimentally induce neuropathy in rats that display Schwann cells pathology and axonal damage (Cavaletti et al., 2007). Multiple myeloma patients treated with bortezomib develop a peripheral neuropathy, which has emerged as dose-limiting toxicity (Cavaletti and Jakubowiak, 2010; Cavaletti, 2011). Based on these reports, it is conceivable that reduced proteasome activity in Schwann cells caused by loss of $\mathrm{Fbxo} 7$ contributes to or even triggers peripheral neuropathy. Also, these findings suggest that it is not just the mere presence of Schwann cells that stimulates the survival of peripheral neurons as shown, for example, in ErbB3-deficient mice (Riethmacher et al., 1997), but likely the intact UPS in Schwann cells that is required to fully support axonal health. Our proteome analyses of the PNS also revealed the downregulation of E2 ubiquitin- 
conjugating enzymes, indicating that the UPS in the sciatic nerve is compromised beyond the loss of Fbxo7.

FBXO7 also is required for mitophagy, a clearance mechanism that is essential for mitochondrial homeostasis (Burchell et al., 2013). Whether or not mitophagy is impaired in oligodendrocytes or in Schwann cells of CNP1-Cre; fl/fl mice remains to be determined. The proteome analyses, however, show the significant downregulation of enzymes required for glycolysis and mitochondrial proteins involved in oxidative phosphorylation in the CNS of these mice. Along with the mitochondrial changes, we observed the increase in GST $\pi 1$. This is consistent with the increased levels of GST $\pi 1$ in MPTP-induced Parkinson model exhibiting oxidative stress (Castro-Caldas et al., 2009). Oligodendrocytes appear to be rather resistant to mitochondrial dysfunction. Ablation of mitochondrial respiration has little or no effect of oligodendrocyte and their associated axons in CNP1-Cre; Cox10fl/fl mice. However, Fünfschilling et al. (2012) demonstrated that loss of respiration in Schwann cells leads to peripheral neuropathy, indicating a sensitivity of Schwann cells to mitochondrial dysfunction. The authors described a progressive loss of myelinated axons in the PNS but no effect on myelination itself, which is comparable with the phenotype we have discovered in our conditional $\mathrm{KO}$ mice.

Together, we show that myelination is entirely independent of FBXO7; the support of axons by myelinating cells, however, is not. This dependence is particularly striking when $\mathrm{Fbxo7}$ is already ablated during development. The loss of $\mathrm{Fbxo} 7$ triggers a peripheral neuropathy and signs of degeneration in the CNS. The global assessment of protein changes in myelinating cells also supports the notion that FBXO7's role in UPS regulation and mitochondrial function contributes to the inability of these cells to support axonal health, identifying FBXO7 as an essential factor of the axon-myelin unit.

\section{References}

Aartsma-Rus A, van Putten M (2014) Assessing functional performance in the mdx mouse model. J Vis Exp 85:e51303.

Boutry JM, Hauw JJ, Gansmüller A, Di-Bert N, Pouchelet M, Baron-Van Evercooren A (1992) Establishment and characterization of a mouse Schwann cell line which produces myelin in vivo. J Neurosci Res 32:1526.

Burchell VS, Nelson DE, Sanchez-Martinez A, Delgado-Camprubi M, Ivatt RM, Pogson JH, Randle SJ, Wray S, Lewis PA, Houlden H, Abramov AY, Hardy J, Wood NW, Whitworth AJ, Laman H, Plun-Favreau H (2013) The Parkinson's disease-linked proteins Fbxo7 and parkin interact to mediate mitophagy. Nat Neurosci 16:1257-1265.

Castro-Caldas M, Neves Carvalho A, Peixeiro I, Rodrigues E, Lechner MC, Gama MJ (2009) GSTpi expression in MPTP-induced dopaminergic neurodegeneration of C57BL/6 mouse midbrain and striatum. J Mol Neurosci 38:114-127.

Cavaletti G (2011) Bortezomib-induced peripheral neuropathy: facts and genes. Lancet Oncol 12:120-121.

Cavaletti G, Jakubowiak AJ (2010) Peripheral neuropathy during bortezomib treatment of multiple myeloma: a review of recent studies. Leuk Lymphoma 51:1178-1187.

Cavaletti G, Gilardini A, Canta A, Rigamonti L, Rodriguez-Menendez V, Ceresa C, Marmiroli P, Bossi M, Oggioni N, D’Incalci M, De Coster R (2007) Bortezomib-induced peripheral neurotoxicity: a neurophysiological and pathological study in the rat. Exp Neurol 204:317-325.

Chapon F, Latour P, Diraison P, Schaeffer S, Vandenberghe A (1999) Axonal phenotype of Charcot-Marie-Tooth disease associated with a mutation in the myelin protein zero gene. J Neurol Neurosurg Psychiatry 66: 779-782.

Di Fonzo A, Dekker MC, Montagna P, Baruzzi A, Yonova EH, Correia Guedes L, Szczerbinska A, Zhao T, Dubbel-Hulsman LO, Wouters CH, de Graaff E, Oyen WJ, Simons EJ, Breedveld GJ, Oostra BA, Horstink MW, Bonifati
V (2009) FBXO7 mutations cause autosomal recessive, early-onset parkinsonian-pyramidal syndrome. Neurology 72:240-245.

Distler U, Kuharev J, Navarro P, Levin Y, Schild H, Tenzer S (2014) Drift time-specific collision energies enable deep-coverage data-independent acquisition proteomics. Nat Methods 11:167-170.

Distler U, Kuharev J, Navarro P, Tenzer S (2016) Label-free quantification in ion mobility-enhanced data-independent acquisition proteomics. Nat Protoc 11:795-812.

Dong Z, Sinanan A, Parkinson D, Parmantier E, Mirsky R, Jessen KR (1999) Schwann cell development in embryonic mouse nerves. J Neurosci Res 56:334-348.

Eddy NB, Leimbach D (1953) Synthetic analgesics: II. Dithienylbutenyland dithienylbutylamines. J Pharmacol Exp Ther 107:385-393.

Finsterer J, Miltenberger G, Rauschka H, Janecke A (2006) Novel C59T leader peptide mutation in the MPZ gene associated with late-onset, axonal, sensorimotor polyneuropathy. Eur J Neurol 13:1149-1152.

Fledrich R, Stassart RM, Klink A, Rasch LM, Prukop T, Haag L, Czesnik D, Kungl T, Abdelaal TA, Keric N, Stadelmann C, Brück W, Nave KA, Sereda MW (2014) Soluble neuregulin-1 modulates disease pathogenesis in rodent models of Charcot-Marie-Tooth disease 1A. Nat Med 20:1055-1061.

Fortun J, Li J, Go J, Fenstermaker A, Fletcher BS, Notterpek L (2005) Impaired proteasome activity and accumulation of ubiquitinated substrates in a hereditary neuropathy model. J Neurochem 92:1531-1541.

Fortun J, Go JC, Li J, Amici SA, Dunn WA Jr, Notterpek L (2006) Alterations in degradative pathways and protein aggregation in a neuropathy model based on PMP22 overexpression. Neurobiol Dis 22:153-164.

Fünfschilling U, Supplie LM, Mahad D, Boretius S, Saab AS, Edgar J, Brinkmann BG, Kassmann CM, Tzvetanova ID, Möbius W, Diaz F, Meijer D, Suter U, Hamprecht B, Sereda MW, Moraes CT, Frahm J, Goebbels S, Nave KA (2012) Glycolytic oligodendrocytes maintain myelin and longterm axonal integrity. Nature 485:517-521.

Gallyas F (1979) Silver staining of myelin by means of physical development. Neurol Res 1:203-209.

Griffiths I, Klugmann M, Anderson T, Yool D, Thomson C, Schwab MH, Schneider A, Zimmermann F, McCulloch M, Nadon N, Nave KA (1998) Axonal swellings and degeneration in mice lacking the major proteolipid of myelin. Science 280:1610-1613.

Groh J, Weis J, Zieger H, Stanley ER, Heuer H, Martini R (2012) Colonystimulating factor-1 mediates macrophage-related neural damage in a model for Charcot-Marie-Tooth disease type 1X. Brain 135:88-104.

Groh J, Klein I, Hollmann C, Wettmarshausen J, Klein D, Martini R (2015) CSF-1-activated macrophages are target-directed and essential mediators of Schwann cell dedifferentiation and dysfunction in Cx32-deficient mice. Glia 63:977-986.

Gündüz A, Eken AG, Bilgic B, Hanagasi HA, Bilgüvar K, Günel M, Basak AN, Ertan S (2014) FBXO7-R498X mutation: phenotypic variability from chorea to early onset parkinsonism within a family. Parkinsonism Relat Disord 20:1253-1256.

Hall CS, Ballachey EL (1932) A study of the rat's behavior in a field: a contribution to Methof in comparative psychology. Berkeley, CA: University of California.

Holubowska A, Mukherjee C, Vadhvani M, Stegmüller J (2014) Genetic manipulation of cerebellar granule neurons in vitro and in vivo to study neuronal morphology and migration. J Vis Exp 85:e51070.

Jessen KR, Mirsky R (2016) The repair Schwann cell and its function in regenerating nerves. J Physiol 594:3521-3531.

Jessen KR, Morgan L, Stewart HJ, Mirsky R (1990) Three markers of adult non-myelin-forming Schwann cells, 217c(Ran-1), A5E3 and GFAP: development and regulation by neuron-Schwann cell interactions. Development 109:91-103.

Joseph S, Schulz JB, Stegmüller J (2018) Mechanistic contributions of FBXO7 to Parkinson disease. J Neurochem 144:118-127.

Kammers K, Cole RN, Tiengwe C, Ruczinski I (2015) Detecting significant changes in protein abundance. EuPA Open Proteom 7:11-19.

Karlsson U, Schultz RL (1965) Fixation of the central nervous system for electron microscopy by aldehyde perfusion: I. Preservation with aldehyde perfusates versus direct perfusion with osmium tetroxide with special reference to membranes and the extracellular space. J Ultrastruct Res 12:160-186.

Kisselev AF, Goldberg AL (2005) Monitoring activity and inhibition of 26S proteasomes with fluorogenic peptide substrates. Methods Enzymol 398: $364-378$. 
Klein D, Groh J, Wettmarshausen J, Martini R (2014) Nonuniform molecular features of myelinating Schwann cells in models for CMT1: distinct disease patterns are associated with NCAM and c-jun upregulation. Glia 62:736-750.

Kuharev J, Navarro P, Distler U, Jahn O, Tenzer S (2015) In-depth evaluation of software tools for data-independent acquisition based label-free quantification. Proteomics 15:3140-3151.

Laman H, Funes JM, Ye H, Henderson S, Galinanes-Garcia L, Hara E, Knowles P, McDonald N, Boshoff C (2005) Transforming activity of Fbxo7 is mediated specifically through regulation of cyclin D/cdk6. EMBO J 24:3104-3116.

Lappe-Siefke C, Goebbels S, Gravel M, Nicksch E, Lee J, Braun PE, Griffiths IR, Nave KA (2003) Disruption of Cnp1 uncouples oligodendroglial functions in axonal support and myelination. Nat Genet 33:366-374.

Larocca JN, Norton WT (2007) Isolation of myelin. Curr Protoc Cell Biol 33:3.25.1-3.25.19.

Lee Y, Morrison BM, Li Y, Lengacher S, Farah MH, Hoffman PN, Liu Y, Tsingalia A, Jin L, Zhang PW, Pellerin L, Magistretti PJ, Rothstein JD (2012) Oligodendroglia metabolically support axons and contribute to neurodegeneration. Nature 487:443-448.

Leone DP, Genoud S, Atanasoski S, Grausenburger R, Berger P, Metzger D, Macklin WB, Chambon P, Suter U (2003) Tamoxifen-inducible gliaspecific Cre mice for somatic mutagenesis in oligodendrocytes and Schwann cells. Mol Cell Neurosci 22:430-440.

Li GZ, Vissers JP, Silva JC, Golick D, Gorenstein MV, Geromanos SJ (2009) Database searching and accounting of multiplexed precursor and product ion spectra from the data independent analysis of simple and complex peptide mixtures. Proteomics 9:1696-1719.

Lohmann E, Coquel AS, Honoré A, Gurvit H, Hanagasi H, Emre M, Leutenegger AL, Drouet V, Sahbatou M, Guven G, Erginel-Unaltuna N, Deleuze JF, Lesage S, Brice A (2015) A new F-box protein 7 gene mutation causing typical Parkinson's disease. Mov Disord 30:1130-1133.

Luft JH (1961) Improvements in epoxy resin embedding methods. J Biophys Biochem Cytol 9:409-414.

Luong TN, Carlisle HJ, Southwell A, Patterson PH (2011) Assessment of motor balance and coordination in mice using the balance beam. J Vis Exp 49:e2376.

Manca D, Cossu G, Murgia D, Molari A, Ferrigno P, Marcia E, Melis M (2009) Reversible encephalopathy and axonal neuropathy in Parkinson's disease during duodopa therapy. Mov Disord 24:2293-2294.

Matsuura K, Kabuto H, Makino H, Ogawa N (1997) Pole test is a useful method for evaluating the mouse movement disorder caused by striatal dopamine depletion. J Neurosci Methods 73:45-48.

Norton WT, Poduslo SE (1973) Myelination in rat brain: method of myelin isolation. J Neurochem 21:749-757.

Ogawa N, Hirose Y, Ohara S, Ono T, Watanabe Y (1985) A simple quantitative bradykinesia test in MPTP-treated mice. Res Commun Chem Pathol Pharmacol 50:435-441.

Ohsawa Y, Kurokawa K, Sonoo M, Yamada H, Hemmi S, Iwatsuki K, Hagiwara H, Murakami T, Shirabe T, Shimizu T, Sunada Y (2005) Reduced amplitude of the sural nerve sensory action potential in PARK2 patients. Neurology 65:459-462.

Pellow S, Chopin P, File SE, Briley M (1985) Validation of open:closed arm entries in an elevated plus-maze as a measure of anxiety in the rat. J Neurosci Methods 14:149-167.

Rajabally YA, Martey J (2011) Neuropathy in Parkinson disease: prevalence and determinants. Neurology 77:1947-1950.

Reynolds ES (1963) The use of lead citrate at high $\mathrm{pH}$ as an electron-opaque stain in electron microscopy. J Cell Biol 17:208-212.

Riethmacher D, Sonnenberg-Riethmacher E, Brinkmann V, Yamaai T, Lewin GR, Birchmeier C (1997) Severe neuropathies in mice with targeted mutations in the ErbB3 receptor. Nature 389:725-730.

Ritchie ME, Phipson B, Wu D, Hu Y, Law CW, Shi W, Smyth GK (2015) limma powers differential expression analyses for RNA-sequencing and microarray studies. Nucleic Acids Res 43:e47.

Rubinson DA, Dillon CP, Kwiatkowski AV, Sievers C, Yang L, Kopinja J, Rooney DL, Zhang M, Ihrig MM, McManus MT, Gertler FB, Scott ML, Van Parijs L (2003) A lentivirus-based system to functionally silence genes in primary mammalian cells, stem cells and transgenic mice by RNA interference. Nat Genet 33:401-406.

Saab AS, Nave KA (2017) Myelin dynamics: protecting and shaping neuronal functions. Curr Opin Neurobiol 47:104-112.

Saab AS, Tzvetanova ID, Nave KA (2013) The role of myelin and oligodendrocytes in axonal energy metabolism. Curr Opin Neurobiol 23:10651072 .

Schindelin J, Arganda-Carreras I, Frise E, Kaynig V, Longair M, Pietzsch T, Preibisch S, Rueden C, Saalfeld S, Schmid B, Tinevez JY, White DJ, Hartenstein V, Eliceiri K, Tomancak P, Cardona A (2012) Fiji: an opensource platform for biological-image analysis. Nat Methods 9:676-682.

Schneider CA, Rasband WS, Eliceiri KW (2012) NIH image to ImageJ: 25 years of image analysis. Nat Methods 9:671-675.

Schultz RL, Karlsson U (1965) Fixation of the central nervous system for electron microscopy by aldehyde perfusion: II. Effect of osmolarity, $\mathrm{pH}$ of perfusate, and fixative concentration. J Ultrastruct Res 12:187-206.

Senderek J, Hermanns B, Lehmann U, Bergmann C, Marx G, Kabus C, Timmerman V, Stoltenburg-Didinger G, Schröder JM (2000) CharcotMarie-Tooth neuropathy type 2 and P0 point mutations: two novel amino acid substitutions (Asp61Gly; Tyr119Cys) and a possible "hotspot" on Thr124Met. Brain Pathol 10:235-248.

Sereda MW, Nave KA (2006) Animal models of Charcot-Marie-Tooth disease type 1A. Neuromolecular Med 8:205-216.

Shojaee S, Sina F, Banihosseini SS, Kazemi MH, Kalhor R, Shahidi GA, Fakhrai-Rad H, Ronaghi M, Elahi E (2008) Genome-wide linkage analysis of a parkinsonian-pyramidal syndrome pedigree by $500 \mathrm{~K} \mathrm{SNP}$ arrays. Am J Hum Genet 82:1375-1384.

Shy ME, Jáni A, Krajewski K, Grandis M, Lewis RA, Li J, Shy RR, Balsamo J, Lilien J, Garbern JY, Kamholz J (2004) Phenotypic clustering in MPZ mutations. Brain 127:371-384.

Silva JC, Gorenstein MV, Li GZ, Vissers JP, Geromanos SJ (2006) Absolute quantification of proteins by LCMSE: a virtue of parallel MS acquisition. Mol Cell Proteomics 5:144-156.

Steru L, Chermat R, Thierry B, Simon P (1985) The tail suspension test: a new method for screening antidepressants in mice. Psychopharmacology (Berl) 85:367-370.

Storey JD, Tibshirani R (2003) Statistical significance for genomewide studies. Proc Natl Acad Sci U S A 100:9440-9445.

Taly AB, Muthane UB (1992) Involvement of peripheral nervous system in juvenile Parkinson's disease. Acta Neurol Scand 85:272-275.

Tansey FA, Cammer W (1991) A pi form of glutathione-S-transferase is a myelin- and oligodendrocyte-associated enzyme in mouse brain. J Neurochem 57:95-102.

Toth C, Breithaupt K, Ge S, Duan Y, Terris JM, Thiessen A, Wiebe S, Zochodne DW, Suchowersky O (2010) Levodopa, methylmalonic acid, and neuropathy in idiopathic Parkinson disease. Ann Neurol 68:28-36.

Vingill S, Brockelt D, Lancelin C, Tatenhorst L, Dontcheva G, Preisinger C, Schwedhelm-Domeyer N, Joseph S, Mitkovski M, Goebbels S, Nave KA, Schulz JB, Marquardt T, Lingor P, Stegmüller J (2016) Loss of FBXO7 (PARK15) results in reduced proteasome activity and models a parkinsonism-like phenotype in mice. EMBO J 35:2008-2025.

Weis J, Brandner S, Lammens M, Sommer C, Vallat JM (2012) Processing of nerve biopsies: a practical guide for neuropathologists. Clin Neuropathol 31:7-23.

Yalcin-Cakmakli G, Olgiati S, Quadri M, Breedveld GJ, Cortelli P, Bonifati V, Elibol B (2014) A new Turkish family with homozygous FBXO7 truncating mutation and juvenile atypical parkinsonism. Parkinsonism Relat Disord 20:1248-1252.

Zeisel A, Muñoz-Manchado AB, Codeluppi S, Lönnerberg P, La Manno G, Juréus A, Marques S, Munguba H, He L, Betsholtz C, Rolny C, CasteloBranco G, Hjerling-Leffler J, Linnarsson S (2015) Brain structure: cell types in the mouse cortex and hippocampus revealed by single-cell RNAseq. Science 347:1138-1142.

Zhang Y, Chen K, Sloan SA, Bennett ML, Scholze AR, O'Keeffe S, Phatnan HP, Guarnieri P, Caneda C, Ruderisch N, Deng S, Liddelow SA, Zhang C, Daneman R, Maniatis T, Barres BA, Wu JQ (2014) An RNA-sequencing transcriptome and splicing database of glia, neurons, and vascular cells of the cerebral cortex. J Neurosci 34:11929-11947. 